\title{
Adipose Tissue, Inflammation (Meta-inflammation) and Obesity Management
}

\author{
Anna Meiliana ${ }^{1,2,}$, Nurrani Mustika Dewi², Andi Wijaya ${ }^{2,3}$ \\ ${ }^{1}$ Postgraduate Program in Clinical Pharmacy, Faculty of Pharmacy, Padjadjaran University, Jl. Eijkman No.38, Bandung, Indonesia \\ ${ }^{2}$ Prodia Clinical Laboratory, Jl. Cisangkuy No.2, Bandung, Indonesia \\ ${ }^{3}$ Postgraduate Program in Clinical Biochemistry, Faculty of Medicine, Hasanuddin University, Jl. Perintis Kemerdekaan Km.10, Makassar, Indonesia \\ *Corresponding author. E-mail: anna.meiliana@prodia.co.id
}

Received date: Aug 28, 2015; Revised date: Oct 29, 2015; Accepted date: Nov 16, 2015

\section{Abstract}

$\mathrm{B}$ ACKGROUND: Obesity-induced inflammation contributes to the development of type 2 diabetes, metabolic syndrome, and cardiovascular disease.

CONTENT: The last decade has seen a sharp increase in our appreciation for the macrophage as a critical regulator of metabolic status in obesity. Activation of adipose tissue (AT) macrophages within fat depots is coupled with the development of obesity-induced proinflammatory state and insulin resistance (IR). The activation of classically activated M1 macrophages at the expense of antiinflammatory M2 macrophages has been causally linked to the development of AT inflammation and metabolic syndrome, a pathophysiological state aptly termed as 'metainflammation'. It is recognized that several proinflammatory cytokines, including interleukin (IL)-1 $\beta$, are implicated in disrupting insulin signaling. Our developing appreciation of links among obesity, inflammation and cardiovascular

\section{Introduction}

Obesity has increased rapidly and the consequence was explosion of health-related problems including insulin resistance (IR), type 2 diabetes, coronary artery disease, fatty liver disease, some cancers and degenerative diseases. (1-3) Unfortunately the life style modification was not effective in fighting obesity.(4) Regarding to those fact, therefore the most attention is on the understanding of molecular links between obesity and chronic metabolic diseases especially low grade inflammation that mediated disease will require multiple complementary approaches to leverage new concepts into translatable outcomes. Careful characterization of human patients, particularly analysis of AT distribution, will be needed to stratify subjects that are most likely obese/metabolically healthy from those that are obese/metabolically unhealthy.

SUMMARY: It has been suggested that individuals with the condition known as metabolically healthy obese (MHO) may not have the same increased risk for the development of metabolic abnormalities as their non-metabolically healthy counterparts. A complications-centric model for the medical management of obesity emphasizes the identification and staging of complications, and treatment paradigm directed at patients who would gain the most benefit from weight loss.

KEYWORDS: obesity, inflammation, insulin resistance, M1/M2 macrophage.

Indones Biomed J. 2015; 7(3): 129-46 by innate and adaptive immune cells.(5-10)

Adipose Tissue (AT) is a complex endocrine tissue that contains multiple cell types, including adipocytes and adipocyte precursors, vascular cells, immune cells and neuronal cells, which all contribute to the inflammatory response during obesity.(11) Nutritional excess promotes adipocyte expansion, resulting in adipocyte dysfunction. Adipocytes subsequently secrete adipokines, cytokines and chemokines, such as leptin, resistin, tumor necrosis factor (TNF)- $\alpha$, interleukin (IL)-6, and monocyte chemoattractant protein (MCP)-1, those induce the accumulation of immune cells in AT, and the ongoing inflammation causes IR. 
$(12,13)$ In the course of obesity, almost the entire spectrum of immune cells becomes apparent within the AT.(12) Macrophages are abundantly present in AT.

Resident macrophages in lean AT have an antiinflammatory M2-like phenotype characterized by the surface expression of cluster of differentiation (CD)206 and macrophage galactose-type C lectin 1 (MGL-1), produces anti-inflammatory mediators such as IL-10, and play a critical role in the maintenance of AT insulin sensitivity.(14) During obesity, the majority of macrophages recruited have a proinflammatory M1 profile characterized by the expression of CD11c, inducible nitric oxide synthase (iNOS), TNF- $\alpha$, and IL-6 and reside in crown-like structures that surround necrotic adipocytes.(14)

Besides the classical M1 and M2 macrophages, the obese AT contains a mixed macrophage population, that expresses both CD11c and CD206 which also has a proinflammatory phenotype that promotes AT fibrosis and IR.(15) Neutrophils are recruited to the AT within one week after the start of a high-fat diet (HFD), albeit in low numbers. Genetic deficiency and pharmacologic inhibition of neutrophil elastase improve glucose tolerance and insulin sensitivity by the reduced neutrophil elastasemediated degradation of insulin receptor substrate (IRS)-1 and ameliorate AT inflammation due to decreased Toll-like receptor (TLR)-4-dependent expression of proinflammatory mediators in AT macrophages (ATM).(16)

T-cells constitute $\sim 10 \%$ of the stromal vascular fraction (SVF) of lean AT, with $\mathrm{CD}^{+}{ }^{+} \mathrm{T}$ cells outnumbering $\mathrm{CD} 8^{+}$T-cells. Approximately $50 \%$ of these $\mathrm{CD}^{+}$cells are antiinflammatory regulatory T-cells (Tregs), whereas $\mathrm{T}$ helper (Th) $1 \mathrm{CD}^{+}{ }^{+}$cells and $\mathrm{Th} 2 \mathrm{CD}^{+}$cells are present in equal numbers. During the development of diet-induced obesity, the number of AT T-cells increases as does the $\mathrm{CD}^{+} / \mathrm{CD}^{+} \mathrm{T}$-cell ratio, while at the same time the percentage of Tregs decreases dramatically.(17-19) This change in T-cell subsets is mediated by the expression of signal transducer and activator of transcription 3 (STAT3). (20) $\mathrm{CD}^{+}$cells seem to precede macrophage infiltration and promote the recruitment of ATM by secreting MCP1, MCP-3 and regulated on activation, normal $\mathrm{T}$ cell expressed and secreted.(21) In later stages of obesity, both $\mathrm{CD}^{+}$and $\mathrm{CD} 8^{+} \mathrm{T}$-cells are crucial in the recruitment and $\mathrm{M} 1$ polarization of macrophages through interferon (IFN)- $\gamma .(17,21)$ B-cells are recruited to obese AT and increased B-cell activation is observed in obese subjects. Experimental studies have indicated that B-cells from obese mice secrete more proinflammatory (IFN- $\gamma$, IL-6, and IL8) and less anti-inflammatory (IL-5 and IL-10) cytokines. (22) Additionally, during obesity, B-cells are directly or indirectly activated through lipid-induced TLR signaling or through T-cell-dependent mechanisms, respectively, to produce immunoglobulin G2c (auto) antibodies that promote AT inflammation and IR.(11)

A major obstacle to effective obesity treatment is that lost weight tends to be regained over time.(23) Although the mechanisms underlying recovery of lost weight are incompletely understood, a large literature proposes that body fat stores are subject to homeostatic regulation, and that the process occurs in obese as well as normalweight individuals. Caloric restriction for a period of time showed gradually weight lost in most individuals, but then inexorably recovered. This effect involves the capacity of the brain to sense the reduction of body energy stores and activate responses to compensate for this deficit. In simple terms, voluntary weight loss triggers increases appetite and energy efficiency, such that both sides of the energy balance equation shift in favor of weight gain. $(24,25)$ From this perspective, obesity can be viewed as a disorder in which the biologically defended level of body fat mass is increased. Recent findings implicate inflammation in hypothalamic areas for body weight control in this process. These evidences suggests that obesity activates a complex immunological mechanisms involving a delicate interaction between both innate and adaptive immune systems.(11)

\section{AT Expandability Hypothesis}

Anatomically, AT can be divided into truncal or peripheral region. Truncal AT includes subcutaneous fat in thoracic and abdominal region and also intrathoracic and intraabdominal fat depots.(26) Peripheral AT includes subcutaneous depots in upper and lower extremities. Whether accumulation of AT in a particular region contributes to increased risk of IR development and metabolic consequences or not is still controversial.(27) There are also important adipose depots within the abdominal cavity, called visceral AT (VAT), and around other organs, for example, perirenal, epi- and pericardial fats. Perfusion of VAT regulation is potentially very interesting in view of the relationships between VAT and adverse metabolic profile.(28)

VAT has increased metabolic activity, both lipogenesis and lipolysis, compared to other fat depots. Free fatty acid (FFA), product of lipolysis, can directly enter liver via portal circulation and lead to increased lipid synthesis, gluconeogenesis and IR, resulting in hyperlipidemia, glucose intolerance, hypertension, and ultimately atherosclerosis. (29) Excess FFAs can induce peripheral IR by inhibiting skeletal muscle uptake.(26) However, if VAT was a major contributor to metabolic risk, in comparison to other fat 
depots, it should be the main source of systemic FFA flux. Only small portion of total body fat, $15-18 \%$ in men and $7-8 \%$ in women, is located in abdominal cavity.(30) VAT contributes to only $15 \%$ of the total systemic FFAs whereas the majority of FFAs are contributed by nonsplanchnic AT. $(26,31)$ This raises doubt over contribution of VAT to peripheral insulin sensitivity.

However, we have to remember that elevated waist circumference does not always indicate increased visceral adiposity but instead can also indicate increased subcutaneous adiposity. Subcutaneous AT (SAT) represents about $85 \%$ of all body fat. Its primary metabolic role is to regulate storage and mobilization of lipid energy. It stores lipid in the form of triacylglycerol (TG), which can be mobilized, as required by other tissues, in the form of nonesterified fatty acids (NEFA). Neither TG nor NEFA are soluble to any extent in water, and their transport to and out of the tissue requires special transport mechanisms and adequate blood flow. SAT blood flow is therefore tightly linked to the tissue's metabolic function.(28)

Obesity is associated with impaired lipid storage capacity in SAT. Lipid "spillover" which is occurs as a result leads to lipid deposition in VAT and, subsequently, the liver. $(9,32)$ The excess fat triggers inflammatory pathways in VAT, and the propagation of inflammation signals from adipose into other metabolic tissues induces systemic IR, liver steatosis, and further progression of obesity, creating a vicious cycle. $(9,33)$ We concluded that subcutaneous truncal fat plays a major role in obesity-related IR in comparison to intraperitoneal (visceral) or retroperitoneal fat.

Simple explanation for stronger relationship between SAT and insulin sensitivity comes from larger volume of SAT mass. The subcutaneous abdominal fat mass is approximately twice more than intraperitoneal fat mass and total subcutaneous truncal fat mass can be 4-5 times larger than intraperitoneal fat mass.(34-36) Unger and Scherer proposed that lipotoxicity promote IR, hyperlipidemia, elevated abdominal fat, and hypertension, known as metabolic syndrome outriding the onset of type 2 diabetes mellitus onset in obese.(37-39)

The underlying mechanism linking lipotoxic obesity with IR is widely believed to be impaired adipogenesis, which is manifested as the presence of enlarged subcutaneous adipocytes.(40) Larger adipocytes are thought to be close to a hypothesized critical volume where further expansion is no longer possible; therefore, excess lipid is shunted instead to nonATs (skeletal muscle, liver, heart, and pancreas), where it interferes with insulin signaling and causes tissue IR.(41) Enlarged adipocytes may also secrete chemoattractants or have localized hypoxia, which trigger macrophage infiltration and activate the inflammatory process in AT, thus worsening IR.(42,43) AT containing primarily large adipocytes is more insulin resistant, as illustrated by reduced suppression of FFA production, resulting in elevated FFAs, which can directly activate inflammation via TLR.(44)

With the assumption of equal metabolic activity in subcutaneous truncal and intraperitoneal fat, subcutaneous truncal fat should release more FFAs in systemic circulation and should have much larger impact on peripheral insulin sensitivity. As we mentioned earlier, major contributor of FFAs in systemic circulation is nonsplanchnic AT.(27) In comparison to noninflamed subcutaneous abdominal adipose phenotype, inflamed phenotype, characterized by presence of macrophage in crown-like structures, was associated with systemic hyperinsulinemia, IR, impaired endothelium-dependent flow-mediated vasodilatation, and elevated plasma high-sensitivity $\mathrm{C}$-reactive protein (hsCRP) levels. Other investigators have also reported similar association between macrophage infiltration in SAT and IR, and low grade systemic inflammation. $(43,45)$

Obese people who are "metabolically healthy" have greater adipogenesis (smaller subcutaneous fat cells) along with less visceral adiposity and hepatic lipid accumulation, decreased inflammation, and preserved insulin sensitivity compared with metabolically unhealthy obese.(46-48) It shows that individuals with larger fat cells would have less capacity to expand their SAT and would deposit more lipid into ectopic depots, thus worsening the metabolic response.

\section{AT as An Immunologic Organ}

Current approaches for the treatment of obesity, including diet and lifestyle changes, have not been pretty fruitful in curtailing the obesity epidemic.(49) Emerging evidence has stated that obesity is characterized by chronic and low-grade inflammation accompanied by macrophage accumulation in the AT, which eventually leads to metabolic diseases, including IR and type 2 diabetes mellitus .(50-52) Increased ATM play crucial roles in the altered production of proinflammatory cytokines in the AT of obesity.(53) Improved understanding of the immunological processes that regulate obesity may yield new treatments for obesityassociated disorders.

Plenty of immune cells including B-cells, T-cells, macrophages, and neutrophils have been identified in AT. Obesity influences both the quantity and the nature of immune cell subtypes, that emerges as an active immunological organ capable of modifying whole-body metabolism through paracrine and endocrine mechanisms. $\mathrm{AT}$ is a large immunologically active organ during obesity 
and displays hallmarks of both innate and adaptive immune response.(54)

During obesity, AT mass increases by hyperplasia and hypertrophy, the latter being associated with activation of stress signaling pathways in adipocytes resulting cell death. For instance, hypertrophic adipocytes are under constant stress, as evidenced by increase in endoplasmic reticulum (ER) stress, hypoxic responses, release of FFAs and increased production of reactive oxygen species (ROS). (5) Interestingly, immunohistochemical studies showed that the inflammatory macrophages expressing the dendritic cell marker CD11c circumscribe necrotic adipocytes $(14,55)$, by that forming "crown-like" structures $(56,57)$. Multiple studies during the past decade have identified VAT as an important site of residence of leukocytes, including cells of the innate (macrophages and neutrophils) and adaptive immune system (T- and B-cells).(49,58,59) It is clear that AT is a major endocrine organ that controls energy homeostasis. In addition, the presence of a significant number of hematopoietic cells in AT suggests that immune cells may impart unique immunological properties to the AT.(49) For example, $1 \mathrm{~g}$ of enzymatically dispersed AT can contain up to 5 million SVF cells, and after exclusion of adipocytes, $50-65 \%$ of SVF cells are leukocytes.(60) Considering that in severe obesity in humans, the total fat content can constitute up to $50 \%$ of total body mass, AT thus represents an uncharacterized immunological organ. For such an immunological characterization, specific cells in AT must be able to capture, process, present antigens to $\mathrm{T}$ cells

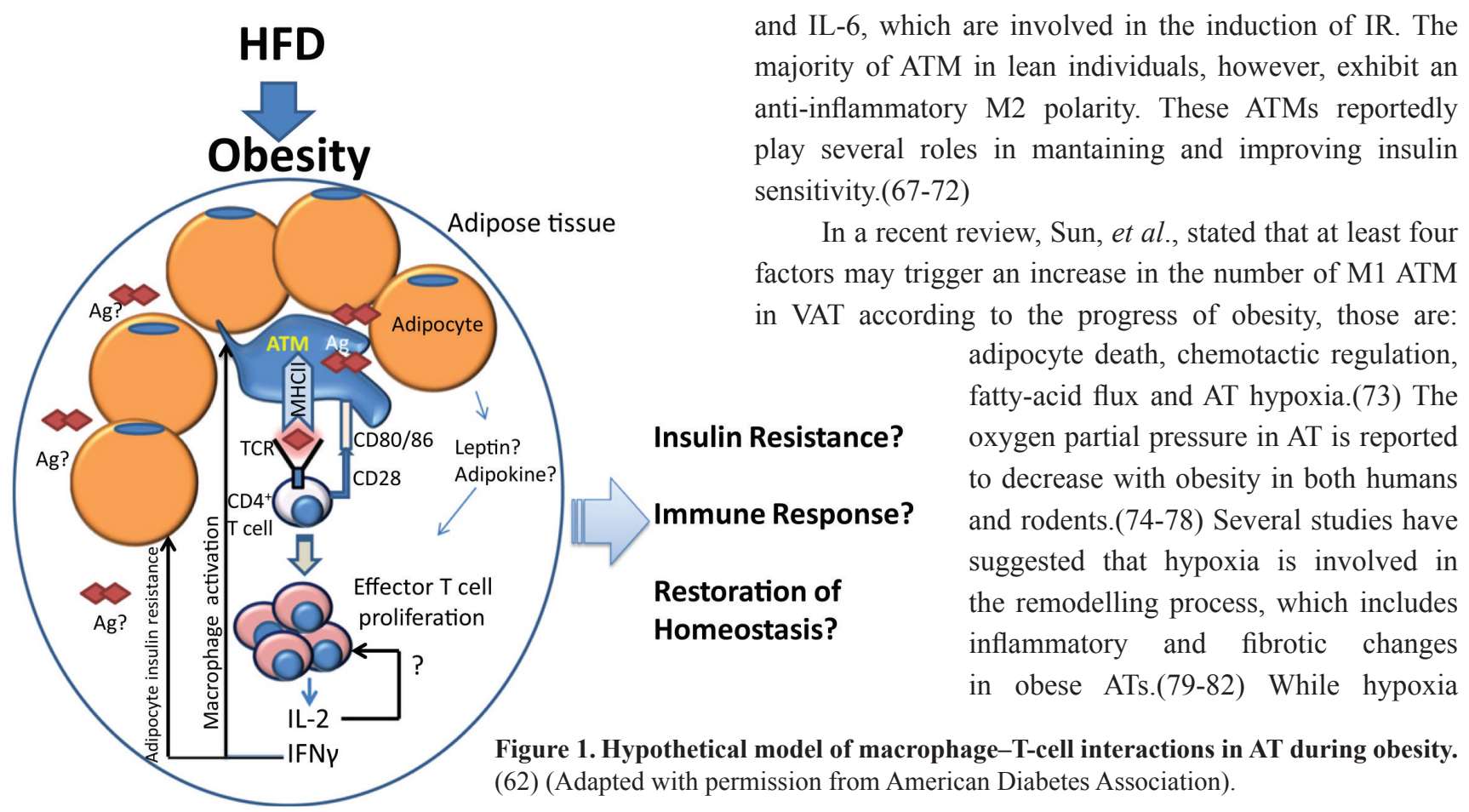

and mount a functional immunological response. Morris, et $a l$., further hypothesize that AT is immunologically aware by providing new evidence that ATMs serve as predominant antigen-presenting cells (APC) that are fully competent to control the antigen-specific T-cell response in the AT of lean as well as obese mice. $(61,62)$

They provide evidence that HFD feeding increases major histocompatibility complex (MHC)-II expression on ATMs and that most of this expression was localized in the "crown-like structures" and "fat-associated lymphoid clusters" in the AT, the major sites of macrophage residence in AT. Furthermore, HFD feeding increases the expression of co-stimulatory molecules on the ATM.(61) In the absence of the co-stimulation signal, the successful interactions of MHC and T-cell receptor (TCR) are not sufficient to induce a T-cell proliferation response and results in T-cell energy. (63) These data again suggest that HFD feeding imparts immunological properties to AT by supporting macrophageT-cell interactions (Figure 1).(62) responses and ATMs perform important roles, such as the production of inflammatory cytokines.(56,64) In general, macrophages exhibit marked functional heterogeneity and local microenvironments influence their activation status and functions. $(65,66)$ Th1 cytokines, such as IFN- $\gamma$, induce classical activation of M1 macrophages, which produce inflammatory mediators. Th2 cytokines, such as IL-4 and IL-13, induce the alternative activation of M2 macrophages, which mediate anti-inflammatory responses. M1 ATMs produce inflammatory cytokines, such as TNF- $\alpha$ and IL-6, which are involved in the induction of IR. The majority of ATM in lean individuals, however, exhibit an insulin in a

ctors may trigger an incease in the number of M1 ATM in VAT according to the progress of obesity, those are: adipocyte death, chemotactic regulation, fatty-acid flux and AT hypoxia.(73) The gen partial pressure in AT is reported and rodents.(74-78) Several studies have suggested that hypoxia is involved in the remodelling process, which includes inflammatory and fibrotic changes in obese ATs.(79-82) While hypoxia
VAT is a major site for such chronic inflammatory

(62) (Adapted with permission from American Diabetes Association). 
in adipocytes is involved in the fibrotic remodelling of AT, hypoxia in macrophages has been implicated in inflammatory changes. However, exactly how, and by what mechanisms, hypoxia affects the characteristics of M1 and M2 ATMs in AT from obese mice and leads to inflammation has not been fully addressed to date.(83)

Persistent state of inflammation known to beresponsible for obesity metabolic dysfunction, as triggered by some immunoreceptors that sense metabolic stress signals. Over the past few years, inflammasomes have emerged as central regulators of the immune response in obesity-mediated inflammation.(60,84-89) Inflammasomes are multiprotein platforms which orchestrate the activation and secretion of IL-1 $\beta$ and IL-18 in response to both pathogen- and dangerassociated signals.(90-92) Structurally, inflammasomes consist of a sensor (an non-obese diabetic-like receptor (NLR) or absent in melanoma (AIM) 2 molecule), the adaptor adipose-derived stem cells (ASC) and caspase-1.(92) Many NLR molecules, including NLRP1, NLRP3 and NLRC4, have been shown to promote caspase-1 activation and downstream release of IL- $1 \beta$ and IL-18 after inflammasome formation.(92) Interestingly, a lot of groups have identified important roles for inflammasomes in both the induction and perpetuation of obesity-driven inflammation. Obesity has been shown to trigger inflammasome activation and IL$1 \beta$ secretion in many metabolic organs (Figure 2).(49)

Activation of the NLRP3 inflammasome results the cleaving of the pro-caspase-1 zymogen to active caspase-1. Caspase- 1 acts post-transcriptionally as a cysteine protease that cleaves pro-IL1 $\beta$ and pro-IL18 into their active forms, leading to their secretion. The NLRP3 inflammasome is able to sense FFAs (88), ATP (93), ceramides (60), glucotoxicity (94), cholesterol (87), amyloid- $\beta(95,96)$, and urate crystals (97). Interestingly the active inflammasome complex is secreted or released during pyroptosis and functional in the extracellular space, producing IL-1 $\beta .(98,99)$
Rather than simple inflammatory disease, obesity and metabolic syndrome represent derangements in macrophage activation with concomitant loss of metabolic coordination. As such, the sequelae of obesity are as much products of the loss of positive macrophage influences as the presence of deleterious inflammation. The therapeutic implications of this conclusion are profound because they recommend that pharmacologic targeting of macrophage activation, rather than purely inflammation, might be efficacious in treating this global epidemic.(100)

\section{Adipocyte Remodeling}

Obesity is characterized by the accumulation of fat mass and is often associated with AT dysfunction.(101) Expansion of AT can be achieved by hyperplasia (increase in adipocyte number) or hypertrophy (increase in adipocyte size) or the combination of both.(102,103) AT can respond rapidly and dynamically to alterations in nutrient deprivation and excess through adipocyte hypertrophy and hyperplasia, thereby fulfilling its major role in whole body energy homeostasis.(73) AT remodeling is an ongoing process that is pathologically accelerated in the obese state, and thus, features such as reduced angiogenic remodeling, extracellular matrix (ECM) overproduction, a heightened state of immune cell infiltration and subsequent proinflammatory responses prevail in many obese fatpads.(104) However, not all AT expansion is necessarily associated with pathological changes. The concept of "metabolically healthy obese (MHO)" suggests that some individuals can preserve systemic insulin sensitivity on the basis of "healthy" AT expansion (105), bypassing all of the aforementioned pathological consequences associated with obesity (37), thereby also avoiding the obesity-associated lipotoxic side effects.

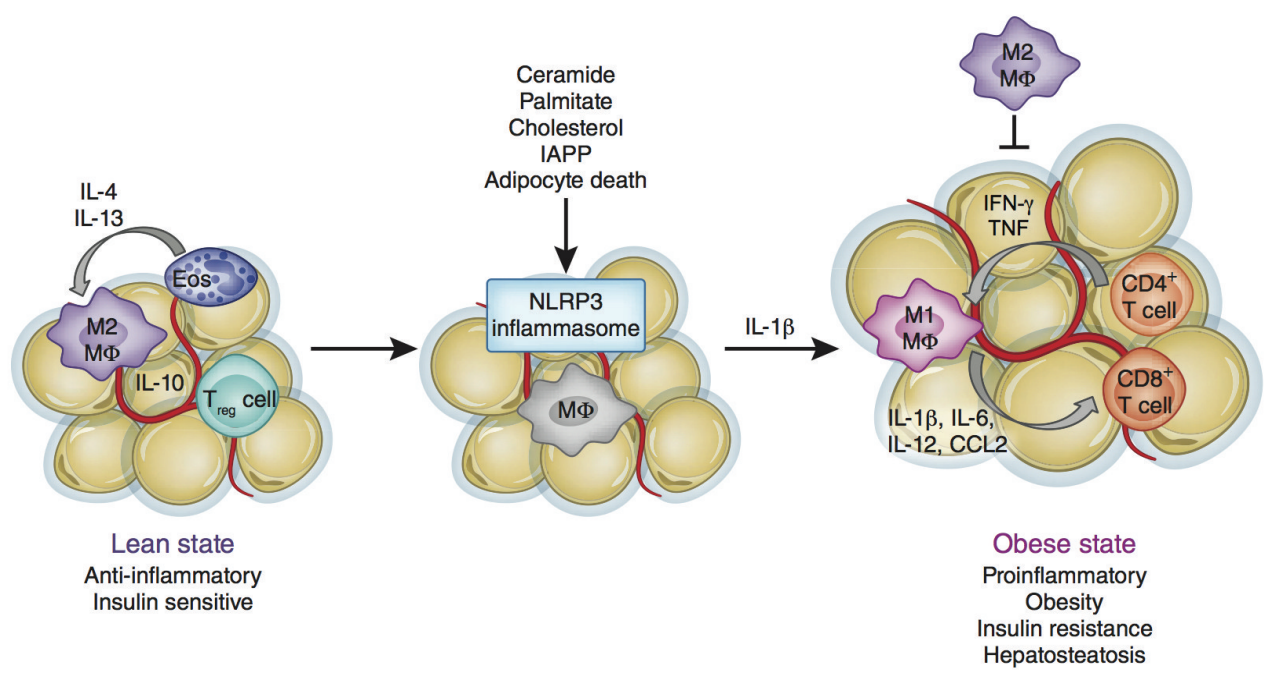

Figure 2. Inflammasomes fuel obesity-induced inflammation. In the lean state, M2 macrophages and Treg cells help restrain inflammation in AT and maintain metabolic homeostasis. (49) M $\phi$ : Macrophage, Eos: Eosinophil, IAPP: Islet amyloid polypeptide, CCL2: Chemokine (C-C motif) ligand 2. (Adapted with permission from Nature Publishing Group). 
The remodeling capacity of AT through hypertrophy and hyperplasia is physiologically important to respond to alterations in energy balance. The pathological acceleration of AT remodeling in the obese state is associated with countless of effects such as hypoxia, cell death, altered adipokine profile, and inflammation and contributes to the clinical adverse consequences of obesity. $(73,106)$ Particularly AT inflammation is regarded as a major pathological factor. $(56,64)$ In 2003, two independent articles in the Journal of the Clinical Investigation highlighted the infiltration of macrophages into expanding AT as an important physiological phenomenon. $(56,64)$ While not only opening up a newfound fundamental role for the macrophage in metabolism, these reports also fueled the publication of numerous additional papers, thus firmly establishing the phenomenon of a macrophage-orchestrated inflammatory response co-existing with obesity-induced IR. Supporting this hypothesis, large clusters of macrophagerelated inflammatory genes were identified as significantly altered in obese AT. $(64,73)$

In order to expand health and properly, adipocytes need a well coordination between the oxygen diffusion limit and promptly many cell types responses, including endothelial precursor cells, immune cells and preadipocytes. (73) A master regulator of hypoxia and oxygen homeostasis is hypoxia-inducible factors (HIF)-1. Several important hypoxia-associated genes, such as leptin and vascular endothelial growth factor (VEGF), are directly regulated by HIF-1.(107) As a transcription factor, HIF-1 functions as a heterodimer, consisting of an oxygen sensitive HIF$1 \alpha$ subunit and a constitutively expressed HIF-1 $\beta$ subunit. While HIF- $1 \alpha$ synthesis is $\mathrm{O}_{2}$ independent, its degradation is enhanced under normoxic conditions.(108) As such, $\mathrm{O}_{2}$ can mediate the prolyl hydroxylation of HIF-1 $\alpha$, which subsequently facilitates ubiquitination by ubiquitin $\mathrm{E} 3$ ligase. This ligase contains a von Hippel-Lindau tumor-suppressor protein, which specifically recognizes the hydroxylated form of HIF- $1 \alpha$ and targets it for ubiquitination and degradation.

As the result of this aberrant HIF-mediated transcriptional program, the ECM in white AT (WAT) accumulates fibrillar collagens. The upregulation of ECM then causes local fibrosis, and that hypoxia-induced fibrosis in AT may be a key factor that ultimately stimulates the local inflammatory responses. Although adipocyte is the key player orchestrating local changes in the microenvironment, much evidence also points toward pivotal role for macrophages in such remodeling events. Resident ATMs display remarkable heterogeneity in their activities and functions (65), largely reflecting the complex events occurring in AT during metabolic and immune perturbations (73).
In 2007, Saltiel and colleagues proposed a model of "phenotypic switching" that captured the very essence by which enhanced ATM infiltration exacerbates the milieu of obesity-related inflammation.(14) Their model emphasized that obesity is accompanied by a transformation in the polarized states of macrophages, from an antiinflammatory "alternatively activated" M2 form which primarily accumulates during negative energy balance (109), to a more proinflammatory "classically activated" M1 form (110). The M1 population demonstrates a positive correlation with IR and dominates in states of overnutrition by targeting FFAmediated increases in proinflammatory responses. $(110,111)$ The polarization of resident macrophages will go toward an M2 status in lean states, presented by the expression of F4/80, CD301, IL-10, and arginase 1 expression as its hallmark (14), and iNOS activity inhibition.(112) Thus adipocyte normal function during the increasing AT mass will be preserved by promoting tissue repair and angiogenesis.(113,114) Conversely, M1 macrophages, induced by lipopolysaccharide and the Th1 cytokine IFN- $\gamma$, express a repertoire of proinflammatory factors, which include F4/80, CD11c, TNF- $\alpha$, IL-6, iNOS, and C-C motif chemokine receptor 2 (CCR2).(14,110)

Taken together, these studies suggest that a delicate balance of polarized populations of macrophages is necessary to maintain adequate adipocyte function. Identifying factors that quench inflammatory signals in AT through modification of ATMs to retain an M2 polarization, or by triggering the phenotypic switch from M1 to M2, may be beneficial to preserve adequate adipocyte function and insulin action in an obese.(73)

An important distinction needs to be established between healthy fat pad expansion and pathological fat pad expansion (Figure 3). The healthy expansion as an enlargement of the fat pad mass through enhanced recruitment of adipocyte precursor cells that are differentiated into small adipocytes, along with the recruitment of other stromal cell types with appropriate ratios, and subsequent vascularization, minimal induction of ECM and minimal inflammation. In contrast, pathological expansion of AT can be described by rapid growth of the fat pad through enlargement of existing fat cells, a high degree of macrophage infiltration, limited vessel development, and massive fibrosis.(115) Such pathological expansion is associated with chronic inflammation, which ultimately results in the development of systemic IR.(73)

Adipocytes are enmeshed in a dense network of ECM. $(116,117)$ The ECM not only functions to provide mechanical support for a fat pad, but also regulates the physiological and pathological events of AT remodeling 
through a variety of signaling pathways.(118) During AT expansion, the ECM actively remodels to accommodate the growth. Several ECM components are upregulated during fat mass expansion in states of obesity. $(119,120)$ AT fibrosis, with its associated reduced plasticity, is therefore a key hallmark of the metabolically dysfunctional AT. Collagen VI, for example, is a collagen complex that is highly enriched in the ECM of AT.(118) Studies demonstrated that the weakening of the ECM that surrounds AT by elimination of collagen VI leads to improved survival rates of adipocytes and improvements in metabolism.(118) Others have further reported correlations between elevated collagen VI levels, hyperglycemia and IR.(120,121)

Metabolism and immunity are two fundamental systems. The presence of immune cells, such as macrophages, in metabolic tissues, suggests dynamic, ongoing crosstalk between these two regulatory systems.(57) The complex events that must occur in order for an organ such as AT to rapidly remodel and either release or accept a large number of calorically dense lipids that have the potential to be potently cytotoxic. A well-orchestrated set of interactions between a number of critical cell types has to take place in a defined chronological order, with many pathological changes that can occur during that process.

\section{Adiposopathy and Adipocyte Dysfunction}

The problems associated with obesity develop initially as a problem related to energy storage, thereby placing WAT at the front lines. In addition to energy storage, WAT also acts to buffer postprandial amount of circulating fatty acids, so excessive lipid won't be accumulated in peripheral tissue (121), and most prominent energy-storing cells in WAT, adipocytes, secrete hormones called adipokines that affect a diverse array of local and systemic functions. WAT consists of a SVF comprised of preadipocytes, endothelial cells, fibroblasts, macrophages, monocytes, and lymphocytes, which also holds important metabolic and immunological roles.(122)

Adiposity is excessive AT. Those with adiposity are characterized as being overweight or obese. Obesity is described as an independent risk factor for cardiovascular disease (CVD).(123) Adiposity is pathological to the cardiovascular system through excessive fat-mass mechanisms and through adipocyte and AT dysfunction. (124) Adiposopathy (or "sick fat") is defined as pathologic AT anatomic/functional disturbances promoted by positive caloric balance in genetically and environmentally susceptible individuals that result in adverse endocrine and immune responses that may directly promote CVD, and may cause or worsen metabolic disease. Because many of these metabolic diseases are major CVD risk factors (e.g., type 2 diabetes mellitus, high blood pressure, and dyslipidemia), adiposopathy also indirectly increases CVD risk.(125-128)

AT is a loose fibrous connective tissue packed with many cells (called "adipocytes") surrounded by collagen, nerves, and blood vessels that are specialized for storage of triglycerides more commonly referred to as "fats".(123) AT's supporting framework contains SVF cells, which include

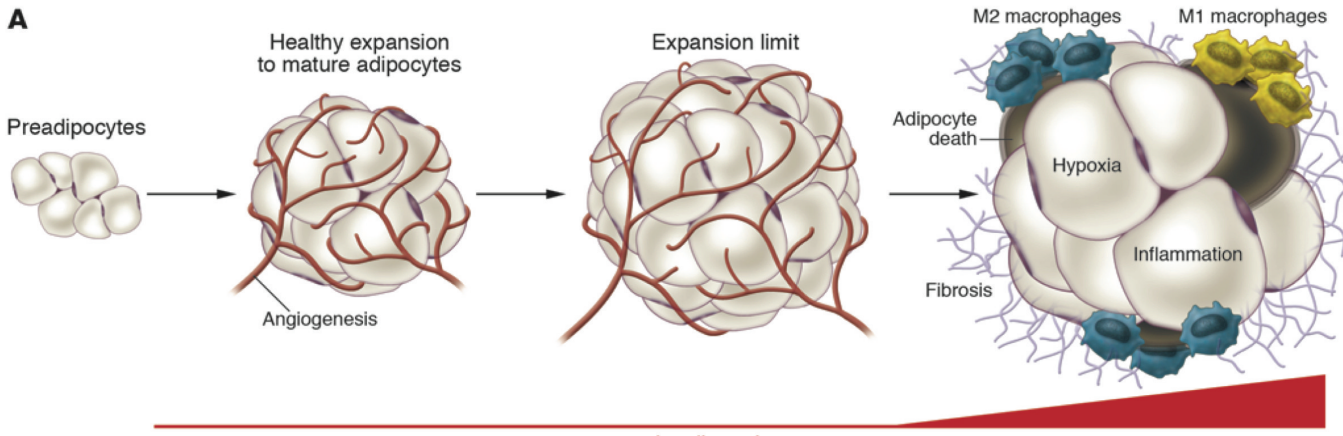

Insulin resistance

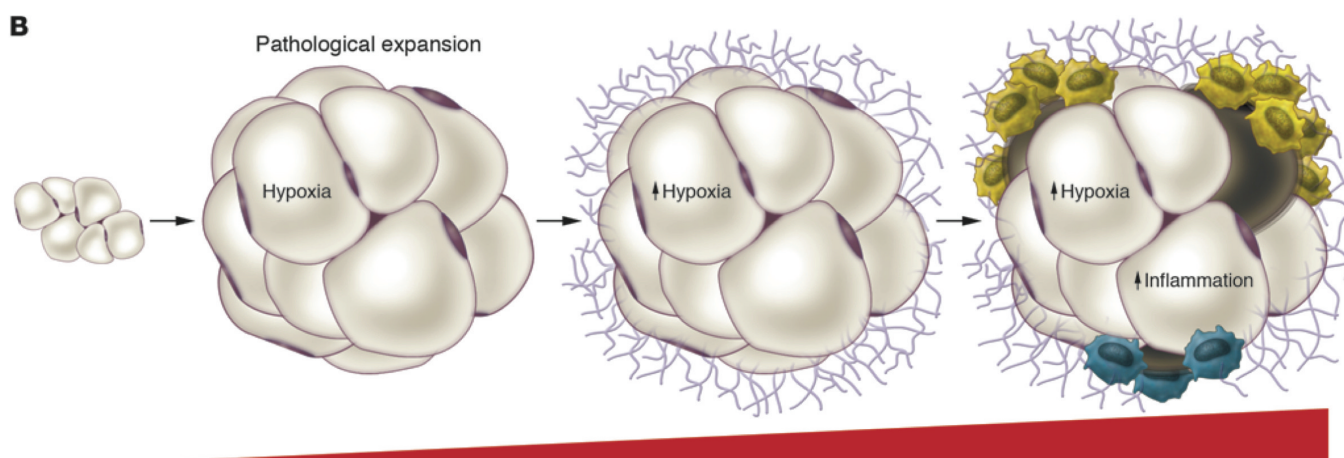

Figure 3. Healthy and unhealthy AT expansion. A: Healthy AT expansion consists of an enlargement of AT through effective recruitment of adipogenic precursor cells to the adipogenic program, along with an adequate angiogenic response and appropriate remodeling of the ECM. There are strong individual differences with respect to the potential for AT expansion. $\mathbf{B}$ : In contrast, pathological AT expansion consists of massive enlargement of existing adipocytes, limited angiogenesis, and ensuing hypoxia.(73) (Adapted with permission from American Society for Clinical Investigation). 
mesenchymal cells, fibroblasts, preadipocytes, endothelial precursor cells, smooth muscle cells, blood cells, and immune cells.(129) In addition to how fat is stored and where fat is stored, other determinants of the pathogenic potential of expanding AT include the interdependent physiologic processes of angiogenesis and ECM remodeling.(124) If an increase in fat storage results in excessive adipocyte enlargement, then adipocyte hypertrophy may contribute to intracellular hypoxia. $(130,131)$ Additionally, when fat accumulation outpaces angiogenesis, then a relative lack of blood flow may result in both cellular and AT hypoxia. $(74,132)$ As with other body tissues (e.g., heart), cellular and tissue adipose hypoxia contributes to cellular and organ dysfunction (132), contributes to proinflammatory responses, and all may contribute to the onset or worsening of metabolic disease (133)

Hypoxic AT has unique alterations that are likely contributors toward the link of obesity with its comorbidities. Fibrosis is a hallmark of metabolically dysfunctional AT. Adipocytes are surrounded by a network of ECM proteins that serve as mechanical support and that respond to different signaling events.(117) Maintaining a high degree of flexibility of the ECM allows AT to expand in a healthy manner, without adverse metabolic consequences. Over the course of the development of obesity, increased interstitial fibrosis in WAT may decrease ECM flexibility and reduce the tissue plasticity, which ultimately leads to adipocyte dysfunction. Of note, abnormal collagen deposition, a hallmark of fibrosis development in AT, is tightly associated with tissue inflammation characterized by infiltration of macrophages and many other immune cells.(73) Thus, fibrosis is increasingly appreciated as a major player in AT dysfunction.(134)

"Sick" adipocytes termed to the disrupted physiological function of fat-cell organelles characterized by increased markers of intracellular ER stress and mitochondrial dysfunction associated with inflammation, cellular dysfunction, and metabolic disease due to excessive adipocyte hypertrophy.(131,135-137) The endoplasmic reticulum is a membrane system of folded sacs and interconnected channels that serves as a site for protein and lipid synthesis, also transport proteins and carbohydrates so the normal cellular functions can take place. Mitochondria are membrane-enclosed organelles that contain enzymes responsible for transforming nutrients into cellular energy through the production of adenosine triphosphate. Increased markers of adipocyte mitochondrial stress are associated with obesity, IR, and type 2 diabetes mellitus.(138)

AT dysfunction belongs to the early abnormalities in the development of obesity and seems to be an important mechanism determining the individual risk to develop metabolic and cardiovascular comorbidities.(129,131,139141) AT dysfunction may develop under conditions of continuous positive energy balance in patients with an impaired expandability of SAT.(142) It has been recently proved that SAT has a higher capacity to expand its capillary network than VAT. With increasing fat accumulation, this capacity decreases.(143) The decrease in SAT angiogenesis correlates with IR and suggests that impaired stem cell vascularization capacity may contribute to metabolic diseases.(143)

SAT and VAT are often described as two intrinsically different organs, with different genetic lineages, whose accumulation promotes different, if not opposing health consequences.(144) Peripheral SAT is often described as 'protective'.(145) Meanwhile, VAT is often described as 'pathologic' (i.e. a 'unique pathogenic fat depot'). (146) However, both SAT and VAT have 'protective' and 'pathologic' properties.(147) From an organ standpoint, SAT, VAT, and other fat depots are globally increased during positive caloric balance.(145) From a cellular standpoint, adipocyte size may be globally regulated, independent of the variations in body fat distribution.(148) This supports the interconnectivity and interdependency of body fat depots and adipocytes, wherein AT's pathogenic potential might best be based upon the global assessments of AT function or dysfunction, rather than assigning the binary 'protective' and 'pathologic' labeling, depot-by-depot, adipocyte-byadipocyte.(147)

The inability to store excess calories in "healthy" subcutaneous fat depots may represent a critical node in the development of subsequent ectopic fat deposition in visceral depots, the liver and other cell types (Figure 4).(130,140,149) This may initiate several mechanisms including adipocyte hypertrophy, hypoxia in AT, several AT stresses, autophagy and inflammation which are activated either as a sequence or in parallel, ultimately leading to AT dysfunction.(150) Increased visceral adiposity often shares common pathologic processes leading to the adiposopathic accumulation of other fat depots, as well as lipotoxic fatty infiltration of nonadipose organs.

Central obesity is a clinical marker for adiposopathy. Increased waist circumference, reflecting increased VAT as a surrogate marker for SAT dysfunction, and a shared pathogenic fat accumulation process and fatty infiltration of nonadipose body organs. AT has long been recognized as the body's largest pool of free cholesterol. Through multiple release and uptake pathways, the adipocyte establishes a communication between its free cholesterol depot and the blood cholesterol pool and in turn maintains cellular 


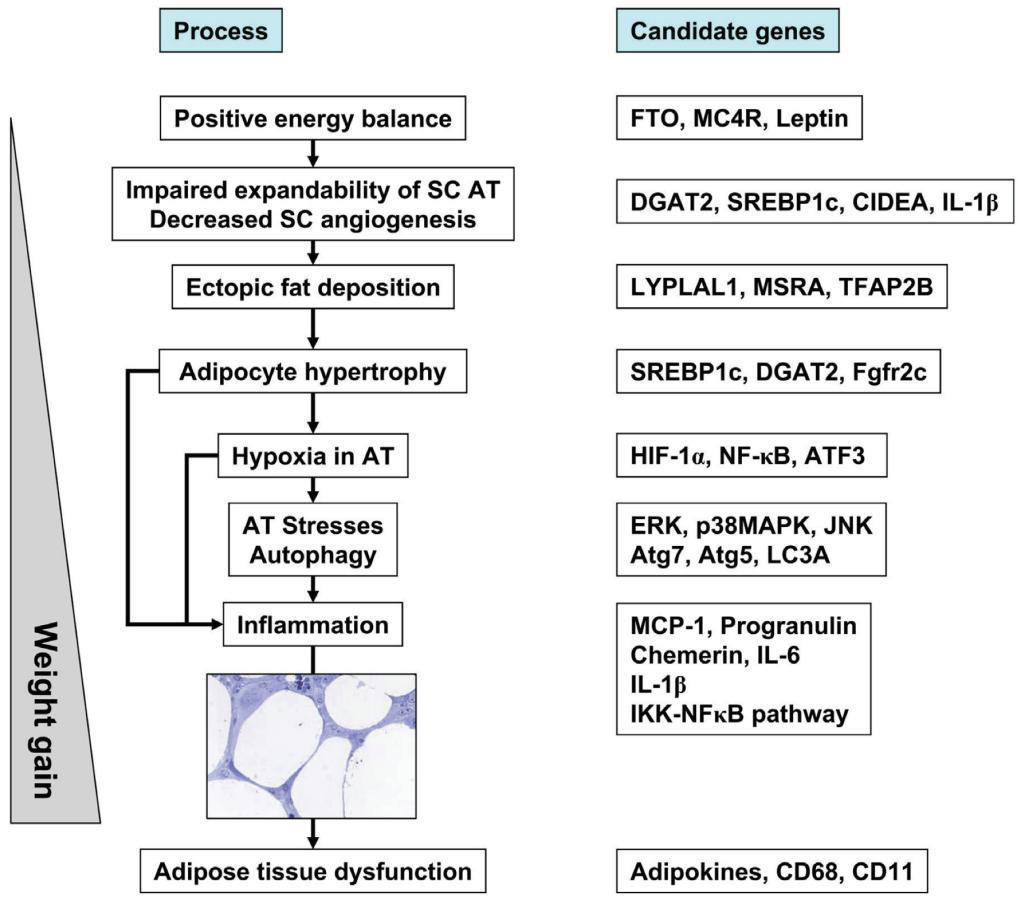

Figure 4. Model for the development of AT dysfunction. With continued overeating and a positive energy balance fat accumulation increases. The majority of patients with obesity exhibit an impaired expandability of SAT which may initiate a sequence of pathogenic factors causing impaired AT function.(149) SC: Subcutaneous, FTO: Fatmass and obesity associated, MC4R: Melanocortin 4 receptor, DGAT2: Diacylglycerol O-acyltransferase 2, SREBP1c: Sterol regulatory element-binding protein 1c, CIDEA: Cell death-inducing DFFA-like effector a, LYPLAL1: Lysophospholipase-like 1, MSRA: Methionine sulfoxide reductase A, TFAP2B: Transcription factor activating enhancer binding protein-2 beta, Fgfr2c: Fibroblast growth factor receptor 2c, NF-кB: Nuclear factor kappa-beta, ATF3: Activating transcripsion factor 3; ERK: Extracellular regulated kinase, p38MAPK: p38 mitogen-activated protein kinase, JNK: c-Jun NH2-terminal kinase, Atg: Authophagy related, LC3A: light chain 3A, IKK: IкB kinase. (Adapted with permission from Elsevier, Ltd.).

cholesterol homeostasis.(151) Interestingly, cholesterol accumulated within lipid droplets increases proportionally to the triglyseride content $(152,153)$, whereas a decrease in plasma membrane cholesterol has been reported in hypertrophied adipocytes (154), implying that altered cholesterol distribution is a feature of adipocyte hypertrophy per se. Subsequently, several lines of evidence further support the role of cholesterol imbalance on adipocyte dysfunction in the state of obese $(155,156)$.

\section{"Metabolically Healthy" Obesity}

Obesity is typically associated with increased risk of cardiovascular events. However, a subset of obese individuals does not present phenotypic traits that characterize increased cardiovascular risk, such as IR. The condition stated above has been called MHO. Indeed, 10-25\% of obese individuals may not be impacted by metabolic abnormalities (157), which is a substantial number considering that obesity affects 300 million people worldwide. In a sub-analysis of the National Health and Nutrition Examination Surveys $19992004,51.3 \%$ of overweight adults and $31.7 \%$ of obese adults were metabolically healthy as they showed either no or one metabolic syndrome trait.(158) The concept of healthy obesity challenges the notion that all overweight and obese individuals should be treated. Selecting such individuals for watchful surveillance could spare significant amounts of societal and economic resources.(159)

The phenotype of the 'metabolically obese but normal weight (MONW)' individual, first identified by Ruderman and colleagues, and characterized by hyperinsulinemia, hyperglycemia, IR, impaired glucose tolerance, hypercholesterolemia and hypertriglyceridemia, but normal adipocyte volume and BMI, suggests that there must be genes and signal transduction pathways that ordinarily couple obesity to IR, and that these are deficient in certain individuals.(158,160) These characteristics in a lean individual mark a departure from common human patterns, in which metabolic disease is a consequence of weight gain. Yet, these phenotypes are very prevalent. For example, polycystic ovary syndrome (PCOS) has been diagnosed in up to $10 \%$ of one study of women of reproductive age (161) and MONW in $12.7 \%$ of normal-weight subjects in a Korean study (162). Elevated risk for CVD is seen among both MONW (163) and PCOS individuals (161), as well as elevated risk for hypertension, type 2 diabetes mellitus and other metabolic complications. Thus, metabolic dysfunction and CVD risk come in many sizes and shapes.(164)

Although adipose depots all increase in volume with obesity, fat deposits in different anatomical regions show depot-associated levels of immune cell infiltration and inflammation, and thus differentially associate with disease. To generalize, SAT is more metabolically 'protective', meanwhile pericardial and other visceral depots are highly correlated with risk for obesity-associated disease, including coronary artery disease.(165-168) The MHO phenotype is strongly associated with a smaller visceral depot, although no necessarily with expanded subcutaneous; the clamped glucose infusion rate strongly correlates with visceral WAT area.(46) Population studies propose that propensity to 
accumulate fat in central oFr peripheral depots has a strong genetic component $(169,170)$, thus certain features of the MHO phenotype are likely to be heritable (171), including body fat distribution. AT depots which preferentially expand in metabolically unhealthy (inflammatory) responses include pericardial (epicardial and interstitial) and visceral depots. AT that preferentially expands in MHO individuals includes widespread subcutaneous depots (Figure 5).(172)

In humans, WAT fibrosis as measured by collagen VI expression is positively correlated with IR and inflammatory markers, such as the number of ATM.(173) The relationship between stress/fibrosis and unhealthy WAT supports a hypothesis that alleles of genes that encode different forms of collagen or enzymes that modify collagen, such as lysyl oxidase $(174,175)$, correlate with the ability of WAT to expand and remodel in obesity while avoiding stress and remaining metabolically healthy. Adipocyte size per se in both omental and subcutaneous depots is also strongly negatively correlated with metabolic health $(46,173)$, with smaller adipocytes and preserved insulin-sensitive glucose transport characteristic of MHO individuals, while some of them based on functional allelic variants of peroxisome proliferator-activated receptor (PPAR)- $\gamma$, PPAR- $\gamma$ coactivator (PGC)-1 $\alpha$, positive regulatory domain-containing 16 (PRDM16) and other adipogenic transcriptional program could expanded subcutaneous WAT then increased adipogenesis.

Not much clinical evidence has yet been assembled to support this idea, even though Patti, et al., noted in a study of Mexican-American subjects that expression of PGC- $1 \alpha$ and PPAR $\gamma$-directed transcriptional networks are decreased in pre-diabetic and type 2 diabetes obese subjects.(176) Their metabolic dysfunction, including reduced oxidative metabolism and attenuated mitochondrial electron transport, is consistent with defective PGC- $1 \alpha$ and PPAR $\gamma$ function, although primary adipogenesis was not studied in this cohort. Well matched MHO and IR obese human subjects should be evaluated for these hypothesized variants.(164)

MHO individuals display a reduced inflammatory profile (47), with reduce hepatosteatosis (48), lower numbers of infiltrating ATMs and crown-like structures in WAT (46) and reduced serum levels of TNF- $\alpha$, monocyte chemotactic protein-1 (48), IL-6 and C-reactive protein (CRP) (46). Elevated serum adiponectin and reduced ATM infiltration are the strongest predictors of preserved ability to clear glucose $(46,177)$; in men, preserved adiponectin levels are associated with a reduced rate of myocardial infarction (178). Adiponectin also promotes protective M2 macrophage differentiation.(179) The mechanistic details of the ways in which macrophages, T-cells, B-cells and adipocytes respond to dietary interventions, bariatric surgery or drug treatment for IR, or can be mobilized for therapeutic benefit, are very poorly understood which has provoked active inquiry.(180) Study of MHO individuals is likely to reveal critical new principles for how their specific anatomical, cellular, immunological and molecular features protect them from type 2 diabetes mellitus and CVD.(181)

A more precise term might be 'metabolically protected obese'. This is because not only are a number of deleterious factors reduced in these individuals, but

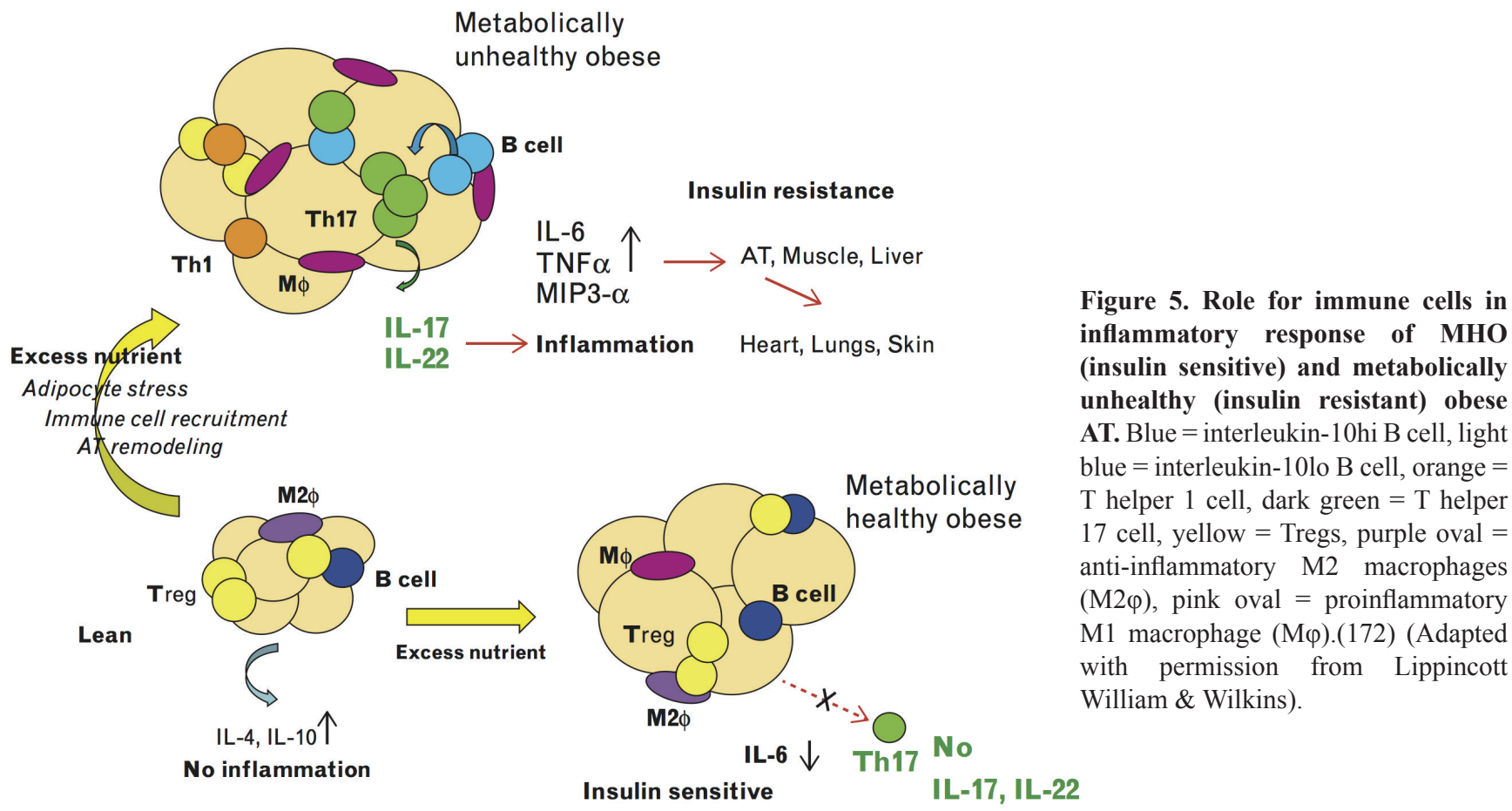


other protective factors are relatively undiminished, such as serum adiponectin.(182,183) In some MHO subjects, adiponectin concentrations even exceed the values seen in normal BMI individuals.(184) Interestingly, a meta-analysis of PCOS women showed that both lean and obese subjects have significantly lower adiponectin than the normal controls (185), consistent with the contention that increased metabolic risk need not be a result of elevated BMI.(164) Triglycerides, HDL cholesterol, and hsCRP may be useful markers for predicting which individuals will develop $\mathrm{MHO}$, and which will go on to develop metabolically unhealthy obesity. MHO may not be a stable condition, because it confers markedly increased risk of developing multiple metabolic abnormalities in the future.(186)

\section{Complication Centric Approach to Obesity Management}

Obesity is arguably the most common medical problem seen today in primary care (187), and is a disease that adversely affects mortality, morbidity, and quality of life as a result of its associated complications $(188,189)$. These complications can broadly be categorized as cardiometabolic, mechanical, and lifestyle based. The health risks associated with being overweight and obese include a range of conditions, including diabetes, CVD, hypertension, dyslipidemia, sleep apnea, some cancers, musculoskeletal disease, infertility, disability, dementia, and mortality. $(1,19,190)$ Moderate weight loss (5-10\%) has been associated with improvements in these obesity-related comorbidities (191), with lifestyle modification, pharmacotherapy, and bariatric surgery representing the three available treatment options. Currently, BMI still used as a predominant measure used to gauge obesity-related disease severity and treatment modalities, but recent understanding in obesity treatment and relationship between BMI and obesity-related complications convince us that this BMI-centric medical model has to be re-examined.

A major shortcoming of BMI as a measure of adiposity is that the numerator (weight) of the index fails to distinguish between lean and fat mass.(192-194) Variables that limit BMI as a comparative measure include aging, sex, physical fitness and muscular build, weight loss with exercise, racial differences, and clinical disease.(195-197) A systematic review found that around $50 \%$ of individuals not labeled as obese by BMI might indeed have excess adiposity, helping to elaborate why BMI is a poor discriminator of cardiovascular risk in people with intermediate BMI (below 30) values.(198)
The relationship between generalized obesity, as measured by the BMI, and its associated comorbidities is complex. Obesity can exacerbate IR and impel cardiometabolic disease progression to metabolic syndrome, prediabetes, diabetes, and CVD. However, IR exists largely independent of BMI, and BMI is a poor predictor of CVD when compared with other measurements such as waist/hip ratio.(199-204) Importantly, up to 30\% of obese individuals $(\mathrm{BMI} \geq 30)$ are relatively insulin sensitive and do not have manifestations of cardiometabolic disease (i.e., the MHO), and up to $30 \%$ of lean individuals are insulin resistant with cardiometabolic disease manifestations.(202,205,206) Thus, obesity is neither necessary nor sufficient to explain the pathophysiology underlying cardiometabolic disease. Similarly, regarding the mechanical complications of obesity, the presence and severity of obstructive sleep apnea (OSA), osteoarthritis, gastroesophageal reflux disease (GERD), and stress incontinence can be poorly correlated with the BMI level.(201)

Denis and Hamilton at the Boston University Medical Center who have investigated the metabolically unhealthy obese, compared to the MHO, and found that a distinguishing factor could be the accumulation of not just visceral body fat but ectopic fat in the pericardial space.(207) Favorable inflammatory status is positively associated with metabolic health in obese and non-obese individuals. These findings are of public health and clinical significance in terms of screening and stratification based on metabolic health phenotype to identify those at greatest cardiometabolic risk for whom appropriate therapeutic or intervention strategies should be developed.(208)

A complications-centric approach to obesity management identifies patients who will benefit most from weight loss, and optimizes patient outcomes, benefit/ risk ratio, and the cost-effectiveness of interventions. In a complications-centric model, the existence and severity of complications at baseline is more important than the baseline BMI itself in determining the treatment modality and intensity for obesity.(209-211) Therefore, in order to develop an appropriate therapeutic strategy, first we have to evaluate the severity of patients' obesity complication.

The clinician should evaluate patients for the metabolic syndrome and prediabetes, as this effectively identifies individuals at high risk for future diabetes and CVD. $(212,213)$ The initial evaluation should also screen for other disease entities that will benefit from weight loss, including nonalcoholic fatty liver disease (NAFLD) and sleep apnea. Finally, mechanical complications such as problematic degenerative joint disease, GERD, stress incontinence, and immobility/disability also have to be evaluate.(198) Obesity 
Table 1. A complications-centric approach for obesity scoring system.

A. Edmonton Obesity Staging System. (198) (Adapted with permission from Lippincott William \& Wilkins).

\begin{tabular}{cll}
\hline Stage & $\begin{array}{l}\text { Cardiometabolic and Mechanical Disease } \\
\text { Complications }\end{array}$ & Functional Impact \\
\hline 0 & No risk factors & No functional impairments or impairments in well-being \\
\hline 1 & $\begin{array}{l}\text { 'Subclinical risk factors': prediabetes, metabolic } \\
\text { syndrome, NAFLD, borderline hypertension, } \\
\text { dyspnea on moderate exertion }\end{array}$ & $\begin{array}{l}\text { Mild functional limitations and impairment of well-being } \\
\text { mild psychopathology, occasional aches and pains }\end{array}$ \\
& $\begin{array}{l}\text { Established chronic disease: T2DM hypertension } \\
\text { sleep apnea, PCOS, osteoarthritis, GERD }\end{array}$ & $\begin{array}{l}\text { Moderate limitations in activities of daily living, moderate } \\
\text { impairment of well-being, and/or moderate } \\
\text { psychopathology (e.g., anxiety disorder) }\end{array}$ \\
\hline 3 & $\begin{array}{l}\text { Established end organ damage: myocardial } \\
\text { infarction heart failure, stroke, diabetes vascular } \\
\text { complications incapacitating osteoarthritis }\end{array}$ & $\begin{array}{l}\text { Significant functional limitations and/or impairment o } \\
\text { well-being }\end{array}$ \\
\hline 4 & Severe end-stage disabilities & $\begin{array}{l}\text { Severe limitations and impairment of well-being severe } \\
\text { disabling psychopathology }\end{array}$ \\
\hline
\end{tabular}

Data from Reference No.210 and 214.

B. Cardiometabolic Disease Staging. (198) (Adapted with permission from Lippincott William \& Wilkins).

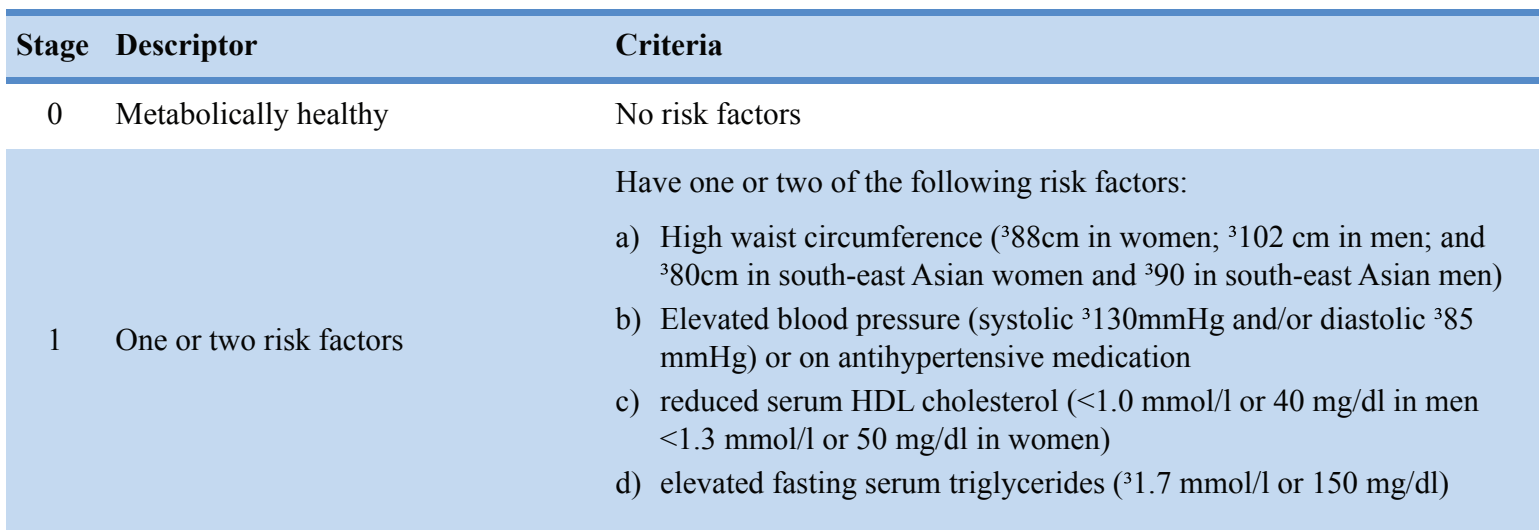

Have only one of the following three conditions in isolation:

a) Metabolic syndrome based on three or more of four risk factors: high waist circumference, elevated blood pressure, reduced HDL-C, and

2 Metabolic syndrome or prediabetes elevated triglycerides

b) Impaired fasting glucose (fasting glucose ${ }^{3} 5.6 \mathrm{mmol} / \mathrm{l}$ or $100 \mathrm{mg} / \mathrm{dl}$ )

c) Impaired glucose tolerance (2-h glucose $17.8 \mathrm{mmol} / 1 \mathrm{or} 140 \mathrm{mg} / \mathrm{dl}$ )

Have any two of the following three conditions:

a) Metabolic syndrome

3 Metabolic syndrome and prediabetes

b) IFG

c) IGT

\section{Have T2DM and/or CVD:}

a) T2DM (fasting glucose ${ }^{3} 126 \mathrm{mg} / \mathrm{dl}$ or 2 -h glucose ${ }^{3} 200 \mathrm{mg} / \mathrm{dl}$ or on antidiabetic therapy)

4 T2DM and/or CVD

b) Active CVD (angina pectoris, or status after a CVD event such as acute coronary artery syndrome, stent placement, coronary artery bypass, thrombotic stroke, nontraumatic amputation due to peripheral vascular disease)

CVD: Cardiovascular disease, HDL-C: High-density lipoprotein cholesterol, IFG: Impaired fasting glucose, IGT: Impaired glucose tolerance, T2DM: Type 2 diabetes mellitus. 
scoring systems that are complications-centric offer a better methodology to gauge severity and direct intervention, but these tools will need to be validated in many settings. The study by Daniel, et al., discusses such scoring systems and some have been published recently such as the Edmonton Obesity Staging System (EOSS) (214) and the American Association of Clinical Endocrinologist (AACE) Complications-Centric Obesity algorithm (212).

The EOSS is a important guideline for obesity management as it integrates an evaluation of the severity of both cardiometabolic disease and mechanical complications together with an assessment of functional impairment. However, it has two limitations. First the assessments are not quantitative and staging depends largely on clinical judgment. Second, it lacks granularity for cardiometabolic disease staging (CMDS). All patients with IR, prediabetes, metabolic syndrome, elevated hepatic transaminases, borderline hypertension, moderate dyspnea on exertion, and mild impairment of well-being are included within stage 1, which encompasses a wide range of risk for (Table 1A). (198)

Garvey and coworkers have recently proposed CMDS System as a guide for treatment of obesity or other interventions intended to treat or prevent diabetes and CVD risk. $(209,211)$ CMDS is a single staging system that provides a quantitative assessment of risk for both future diabetes and all-cause and CVD mortality. CMDS assigns patients to one of five risk categories using quantitative parameters readily available to the clinician, including waist circumference, SBP and DBP, fasting blood levels of glucose, triglycerides, and HDL cholesterol, as well as the 2 -h oral glucose tolerance test value. With advancement from stage 0 to stage 4 , there are significant increments in risk and adjusted hazard ratio for diabetes as validated using the Coronary Artery Risk Development in Young Adults study national cohort, as well as increased risk and hazard ratios for both all-cause and CVD-related mortality in the National Health and Nutrition Examination Survey cohort.(211) This staging system provides a strong predictor of diabetes, CVD mortality, and all-cause mortality independent of BMI (Table 1B).

\section{Conclusion}

Even though BMI is the currently accepted means to define obesity, it is a crude estimate of body fat and the correlation between body fat and risk of mortality from diabetes and heart disease is not perfect. Advancements in treatment modalities for obesity have enabled development of medical models for management. A complications-centric model that employs weight loss as a tool to treat and prevent obesity comorbidities will assure that the aggressiveness of therapy is commensurate with disease severity. This approach is designed to identify patients who will most benefit from weight loss, and optimize patient outcomes, the benefit/risk ratio, and the cost-effectiveness of interventions.

\section{References}

1. Berrington de Gonzalez A, Hartge P, Cerhan JR, Flint AJ, Hannan $\mathrm{L}$, MacInnis RJ, et al. Body-mass index and mortality among 1.46 million white adults. N Engl J Med. 2010; 363: 2211-9.

2. Flegal KM, Graubard BI, Williamson DF, Gail MH. Cause-specific excess deaths associated with underweight, overweight, and obesity. JAMA. 2007; 298: 2028-37.

3. Zheng W, McLerran DF, Rolland B, Zhang X, Inoue M, Matsuo K, et al. Association between body-mass index and risk of death in more than 1 million Asians. N Engl J Med. 2011; 364: 719-29.

4. Leibel RL. Molecular physiology of weight regulation in mice and humans. Int J Obes. 2008; 32 (Suppl 7): S98-108.

5. Hotamisligil GS. Inflammation and metabolic disorders. Nature. 2006; 444: 860-7.

6. Olefsky JM, Glass CK. Macrophages, inflammation, and insulin resistance. Annu Rev Physiol. 2010; 72: 219-46.

7. Shoelson SE, Lee J, Goldfine AB. Inflammation and insulin resistance. J Clin Invest. 2006; 116: 1793-801.

8. Odegaard JI, Chawla A. Mechanisms of macrophage activation in obesity-induced insulin resistance. Nat Clin Pract Endocrinol Metab. 2008; 4: 619-26.

9. Lumeng $\mathrm{CN}$, Saltiel AR. Inflammatory links between obesity and metabolic disease. J Clin Invest. 2011; 121: 2111-7.

10. Ferrante AW Jr. Obesity-induced inflammation: a metabolic dialogue in the language of inflammation. J Intern Med. 2007; 262: 408-14.

11. Seijkens T, Kusters P, Chatzigeorgiou A, Chavakis T, Lutgens E Immune cell crosstalk in obesity: a key role for costimulation? Diabetes. 2014; 63: 3982-91.

12. Mathis D. Immunological goings-on in visceral adipose tissue. Cell Metab. 2013; 17: 851-9.

13. Ouchi N, Parker JL, Lugus JJ, Walsh K. Adipokines in inflammation and metabolic disease. Nat Rev Immunol. 2011; 11: 85-97.

14. Lumeng CN, Bodzin JL, Saltiel AR. Obesity induces a phenotypic switch in adipose tissue macrophage polarization. J Clin Invest. 2007; 117: 175-84

15. Phieler J, Chung KJ, Chatzigeorgiou A, Klotzsche-von Ameln A, Garcia-Martin R, Sprott D, et al. The complement anaphylatoxin $\mathrm{C} 5$ a receptor contributes to obese adipose tissue inflammation and insulin resistance. J Immunol. 2013; 191: 4367-74.

16. Talukdar S, Oh Y, Bandyopadhyay G, Li D, Xu J, McNelis J, et al. Neutrophils mediate insulin resistance in mice fed a high-fat diet through secreted elastase. Nat Med. 2012; 18: 1407-12.

17. Winer S, Chan Y, Paltser G, Truong D, Tsui H, Bahrami J, et al Normalization of obesity-associated insulin resistance through immunotherapy. Nat Med. 2009; 15: 921-9.

18. Feuerer M, Herrero L, Cipolletta D, Naaz A, Wong J, Nayer A, et $a l$. Lean, but not obese, fat is enriched for a unique population of regulatory T cells that affect metabolic parameters. Nat Med. 2009; 15: 930-9. 
19. Chatzigeorgiou A, Karalis KP, Bornstein SR, Chavakis T. Lymphocytes in obesity-related adipose tissue inflammation. Diabetologia. 2012; 55: 2583-92.

20. Priceman SJ, Kujawski M, Shen S, Cherryholmes GA, Lee H, Zhang $\mathrm{C}$, et al. Regulation of adipose tissue $\mathrm{T}$ cell subsets by Stat 3 is crucial for diet-induced obesity and insulin resistance. Proc Natl Acad Sci USA. 2013; 110: 13079-84.

21. Nishimura S, Manabe I, Nagasaki M, Eto K, Yamashita H, Ohsugi M, et al. $\mathrm{CD} 8+$ effector $\mathrm{T}$ cells contribute to macrophage recruitment and adipose tissue inflammation in obesity. Nat Med. 2009; 15: 91420.

22. Winer DA, Winer S, Shen L, Wadia PP, Yantha J, Paltser G, et al. B cells promote insulin resistance through modulation of $\mathrm{T}$ cells and production of pathogenic IgG antibodies. Nat Med. 2011; 17: 610-7.

23. Wadden TA, Sternberg JA, Letizia KA, Stunkard AJ, Foster GD. Treatment of obesity by very low calorie diet, behavior therapy, and their combination: a five-year perspective. Int J Obes. 1989; 13 (Suppl 2): 39-46.

24. Rosenbaum M, Hirsch J, Gallagher DA, Leibel RL. Long-term persistence of adaptive thermogenesis in subjects who have maintained a reduced body weight. Am J Clin Nutr. 2008; 88: 90612.

25. Rosenbaum M, Kissileff HR, Mayer LE, Hirsch J, Leibel RL. Energy intake in weight-reduced humans. Brain Res. 2010; 1350: 95-102.

26. Garg A. Regional adiposity and insulin resistance. J Clin Endocrinol Metab. 2004; 89: 4206-10.

27. Patel P, Abate N. Role of subcutaneous adipose tissue in the pathogenesis of insulin resistance. J Obes. 2013; 2013: 1-5.

28. Frayn KN, Karpe F. Regulation of human subcutaneous adipose tissue blood flow. Int J Obes. 2014; 38: 1019-26.

29. Matsuzawa Y, Shimomura I, Nakamura T, Keno Y, Kotani K, Tokunaga K. Pathophysiology and pathogenesis of visceral fat obesity. Obes Res. 1995; 3 (Suppl 2): 187S-194S.

30. Garg A. Therole of body fat distribution in insulin resistance. In: Reaven GM, Laws A, editors. Insulin Resistance: The Metabolic Syndrome X. New Jersey: Humana Press; 1999. p. 83-96.

31. Jensen MD, Johnson CM. Contribution of leg and splanchnic free fatty acid (FFA) kinetics to postabsorptive FFA flux in men and women. Metabolism. 1996; 45: 662-6.

32. Galgani JE, Moro C, Ravussin E. Metabolic flexibility and insulin resistance. Am J Physiol Endocrinol Metab. 2008; 295: E1009-17.

33. Kodama K, Toda K, Morinaga S, Yamada S, Butte AJ. Anti-CD44 antibody treatment lowers hyperglycemia and improves insulin resistance, adipose inflammation, and hepatic steatosis in dietinduced obese mice. Diabetes. 2015; 64: 867-75.

34. Abate N, Garg A, Peshock RM, Stray-Gundersen J, Grundy SM. Relationships of generalized and regional adiposity to insulin sensitivity in men. J Clin Invest. 1995; 96: 88-98.

35. Abate N, Garg A, Peshock RM, Stray-Gundersen J, Adams-Huet B, Grundy SM. Relationship of generalized and regional adiposity to insulin sensitivity in men with NIDDM. Diabetes. 1996; 45: 1684 93.

36. Ross R, Shaw KD, Rissanen J, Martel Y, de Guise J, Avruch L. Sex differences in lean and adipose tissue distribution by magnetic resonance imaging: anthropometric relationships. Am J Clin Nutr. 1994; 59: 1277-85

37. Unger RH, Scherer PE. Gluttony, sloth and the metabolic syndrome: a roadmap to lipotoxicity. Trends Endocrinol Metab. 2010; 21:34552.

38. Eckel RH, Grundy SM, Zimmet PZ. The metabolic syndrome. Lancet. 2005; 365: 1415-28.

39. Johannsen DL, Tchoukalova Y, Tam CS, Covington JD, Xie W, Schwarz JM, et al. Effect of 8 weeks of overfeeding on ectopic fat deposition and insulin sensitivity: testing the "adipose tissue expandability" hypothesis. Diabetes Care. 2014; 37: 2789-97.

40. Virtue S, Vidal-Puig A. Adipose tissue expandability, lipotoxicity and the metabolic syndrome - An allostatic perspective. Biochim Biophys Acta. 2010; 1801: 338-49.

41. Samuel VT, Shulman GI. Mechanisms for insulin resistance: common threads and missing links. Cell. 2012; 148: 852-71.

42. Skurk T, Alberti-Huber C, Herder C, Hauner H. Relationship between adipocyte size and adipokine expression and secretion. J Clin Endocrinol Metab. 2007; 92: 1023-33.

43. Le KA, Mahurkar S, Alderete TL, Hasson RE, Adam TC, Kim JS, et al. Subcutaneous adipose tissue macrophage infiltration is associated with hepatic and visceral fat deposition, hyperinsulinemia, and stimulation of NF-kB stress pathway. Diabetes. 2011; 60: 2802-9.

44. Shi H, Kokoeva MV, Inouye K, Tzameli I, Yin H, Flier JS. TLR4 links innate immunity and fatty acid-induced insulin resistance. J Clin Invest. 2006; 116: 3015-25.

45. Bremer AA, Devaraj S, Afify A, Jialal I. Adipose tissue dysregulation in patients with metabolic syndrome. J Clin Endocrinol Metab. 2011; 96: E1782-8.

46. Kloting N, Fasshauer M, Dietrich A, Kovacs P, Schön MR, Kern M, et al. Insulin-sensitive obesity. Am J Physiol Endocrinol Metab. 2010; 299: E506-15.

47. Karelis AD, Faraj M, Bastard JP, St-Pierre DH, Brochu M, Prud'homme $\mathrm{D}$, et al. The metabolically healthy but obese individual presents a favorable inflammation profile. J Clin Endocrinol Metab. 2005; 90: 4145-50.

48. O’Connell J, Lynch L, Hogan A, Cawood TJ, O'Shea D. Preadipocyte factor-1 is associated with metabolic profile in severe obesity. J Clin Endocrinol Metab. 2011; 96: E680-4

49. Kanneganti TD, Dixit VD. Immunological complications of obesity. Nat Immunol. 2012; 13: 707-12.

50. Wellen KE, Hotamisligil GS. Inflammation, stress, and diabetes. J Clin Invest. 2005; 115: 1111-9.

51. Olefsky JM, Glass CK. Macrophages, inflammation, and insulin resistance. Annu Rev Physiol. 2010; 72: 219-46.

52. Donath MY, Shoelson SE. Type 2 diabetes as an inflammatory disease. Nat Rev Immunol. 2011; 11: 98-107.

53. Choe SS, Shin KC, Ka S, Lee YK, Chun JS, Kim JB. Macrophage HIF-2 $\alpha$ ameliorates adipose tissue inflammation and insulin resistance in obesity. Diabetes. 2014; 63: 3359-71.

54. Grant RW, Dixir VD. Adipose tissue as an immunological organ. Obesity. 2015; 23: 512-8.

55. Cinti S, Mitchell G, Barbatelli G, Murano I, Ceresi E, Faloia E, et al. Adipocyte death defines macrophage localization and function in adipose tissue of obese mice and humans. J Lipid Res. 2005; 46: 2347-55.

56. Weisberg SP, McCann D, Desai M, Rosenbaum M, Leibel RL, Ferrante AW Jr. Obesity is associated with macrophage accumulation in adipose tissue. J Clin Invest. 2003; 112: 1796-808.

57. Chawla A, Nguyen KD, Goh YP. Macrophage-mediated inflammation in metabolic disease. Nat Rev Immunol. 2012; 11: 738-49.

58. Hotamisligil GS, Erbay E. Nutrient sensing and inflammation in metabolic diseases. Nat Rev Immunol. 2008; 8: 923-34.

59. Osborn O, Olefsky JM. The cellular and signaling networks linking the immune system and metabolism in disease. Nat Med. 2012; 18: 363-74.

60. Vandanmagsar B, Youm YH, Ravussin A, Galgani JE, Stadler K, Mynatt RL, et al. The NLRP3 inflammasome instigates obesityinduced inflammation and insulin resistance. Nat Med. 2011; 17: 179-88.

61. Morris DL, Cho KW, Delproposto JL, Oatmen KE, Geletka LM, Martinez-Santibanez G, et al. Adipose tissue macrophages function 
as antigen-presenting cells and regulate adipose tissue $\mathrm{CD} 4+\mathrm{T}$ cells in mice. Diabetes. 2013; 62: 2762-72.

62. Dixit VD. Adipose tissue macrophages are innate to the immunological awareness of adipose tissue. Diabetes 2013; 62: 2656-8.

63. Janeway CA Jr, Medzhitov R. Innate immune recognition. Annu Rev Immunol. 2002; 20: 197-216.

64. Xu H, Barnes GT, Yang Q, Tan G, Yang D, Chou CJ, et al. Chronic inflammation in fat plays a crucial role in the development of obesity-related insulin resistance. J Clin Invest. 2003; 112: 1821-30.

65. Gordon S, Taylor PR. Monocyte and macrophage heterogeneity. Nat Rev Immunol. 2005; 5: 953-64.

66. Mantovani A, Sica A, Sozzani S, Allavena P, Vecchi A, Locati M. The chemokine system in diverse forms of macrophage activation and polarization. Trends Immunol. 2004; 25: 677-86.

67. Fujisaka S, Usui I, Bukhari A, Ikutani M, Oya T, Kanatani Y, et al. Regulatory mechanisms for adipose tissue M1 and M2 macrophages in diet-induced obese mice. Diabetes. 2009; 58: 2574-82.

68. Fujisaka S, Usui I, Kanatani Y, Ikutani M, Takasaki I, Tsuneyama $\mathrm{K}$, et al. Telmisartan improves insulin resistance and modulates adipose tissue macrophage polarization in high-fat-fed mice. Endocrinology. 2011; 152: 1789-99.

69. Charo IF. Macrophage polarization and insulin resistance: PPARgamma in control. Cell Metab. 2007; 6: 96-8.

70. Odegaard JI, Ricardo-Gonzalez RR, Goforth MH, Morel CR, Subramanian V, Mukundan L, et al. Macrophage-specific PPARgamma controls alternative activation and improves insulin resistance. Nature. 2007; 447: 1116-20.

71. Bouhlel MA, Derudas B, Rigamonti E, Dièvart R, Brozek J, Haulon $\mathrm{S}$, et al. PPARgamma activation primes human monocytes into alternative M2 macrophages with anti-inflammatory properties. Cell Metab. 2007; 6: 137-43.

72. Kang K, Reilly SM, Karabacak V, Gangl MR, Fitzgerald K, Hatano $\mathrm{B}$, et al. Adipocyte-derived Th2 cytokines and myeloid PPARdelta regulate macrophage polarization and insulin sensitivity. Cell Metab. 2008; 7: 485-95

73. Sun K, Kusminski CM, Scherer PE. Adipose tissue remodeling and obesity. J Clin Investig. 2011; 121: 2094-101.

74. Rausch ME, Weisberg S, Vardhana P, Tortoriello DV. Obesity in $\mathrm{C} 57 \mathrm{BL} / 6 \mathrm{~J}$ mice is characterized by adipose tissue hypoxia and cytotoxic T-cell infiltration. Int J Obes. 2008; 32: 451-63.

75. Wang B, Wood IS, Trayhurn P. Dysregulation of the expression and secretion of inflammation-related adipokines by hypoxia in human adipocytes. Pflugers Arch. 2007; 455: 479-92.

76. Larsen OA, Lassen NA, Quaade F. Blood flow through human adipose tissue determined with radioactive xenon. Acta Physiol Scand. 1966; 66: 337-45.

77. Kabon B, Nagele A, Reddy D, Eagon C, Fleshman JW, Sessler $\mathrm{DI}$, et al. Obesity decreases perioperative tissue oxygenation. Anesthesiology. 2004; 100: 274-80.

78. Nishimura S, Manabe I, Nagasaki M, Hosoya Y, Yamashita H, Fujita $\mathrm{H}$, et al. Adipogenesis in obesity requires close interplay between differentiating adipocytes, stromal cells, and blood vessels. Diabetes. 2007; 56: 1517-26.

79. Ye J, Gao Z, Yin J, He Q. Hypoxia is a potential risk factor for chronic inflammation and adiponectin reduction in adipose tissue of ob/ob and dietary obese mice. Am J Physiol Endocrinol Metab. 2007; 293: E1118-28.

80 Hosogai N, Fukuhara A, Oshima K, Miyata Y, Tanaka S, Segawa $\mathrm{K}$, et al. Adipose tissue hypoxia in obesity and its impact on adipocytokine dysregulation. Diabetes. 2007; 56: 901-11.

81. Halberg N, Khan T, Trujillo ME, Wernstedt-Asterholm I, Attie AD, Sherwani $\mathrm{S}$, et al. Hypoxia-inducible factor 1alpha induces fibrosis and insulin resistance in white adipose tissue. Mol Cell Biol. 2009;
29: $4467-83$

82. Divoux A, Tordjman J, Lacasa D, Veyrie N, Hugol D, Aissat A, et al. Fibrosis in human adipose tissue: composition, distribution, and link with lipid metabolism and fat mass loss. Diabetes. 2010; 59: 2817-25.

83. Fujisaka S, Usui I, Ikutani M, Aminuddin A, Takikawa A, Tsuneyama $\mathrm{K}$, et al. Adipose tissue hypoxia induces inflammatory M1 polarity of macrophages in an HIF- $1 \alpha$-dependent and HIF- $1 \alpha$-independent manner in obese mice. Diabetologia. 2013; 56: 1403-12.

84. Stienstra R, van Diepen JA, Tack CJ, Zaki MH, van de Veerdonk FL, Perera D, et al. Inflammasome is a central player in the induction of obesity and insulin resistance. Proc Natl Acad Sci USA. 2011; 108: 15324-9.

85. Stienstra R, Joosten LA, Koenen T, van Tits B, van Diepen JA, van den Berg SA, et al. The inflammasome-mediated caspase-1 activation controls adipocyte differentiation and insulin sensitivity. Cell Metab. 2010; 12: 593-605.

86. Masters SL, Dunne A, Subramanian SL, Hull RL, Tannahill GM, Sharp FA, et al. Activation of the NLRP3 inflammasome by islet amyloid polypeptide provides a mechanism for enhanced IL- $1 \beta$ in type 2 diabetes. Nat Immunol. 2010; 11: 897-904.

87. Duewell P, Kono H, Rayner KJ, Sirois CM, Vladimer G, Bauernfeind FG, et al. NLRP3 inflammasomes are required for atherogenesis and activated by cholesterol crystals. Nature. 2010; 464: 1357-61.

88. Wen H, Gris D, Lei Y, Jha S, Zhang L, Huang MT, et al. Fatty acidinduced NLRP3-ASC inflammasome activation interferes with insulin signaling. Nat Immunol. 2011; 12: 408-15.

89. Henao-mejia J, Elinav E, Jin C, Hao L, Mehal WZ, Strowig T, et al. Inflammasome-mediated dysbiosis regulates progression of NAFLD and obesity. Nature. 2012; 482: 179-85.

90. Kanneganti TD, Lamkanfi M, Nunez G. Intracellular NOD-like receptors in host defense and disease. Immunity. 2007; 27: 549-59.

91. Kanneganti TD. Central roles of NLRs and inflammasomes in viral infection. Nat Rev Immunol. 2010; 10: 688-98.

92. Lamkanfi M, Vande Walle L, Kanneganti TD. Deregulated inflammasome signaling in disease. Immunol Rev. 2011: 243; 163 73.

93. Mariathasan S, Weiss DS, Newton K, McBride J, O'Rourke K, RooseGirma $\mathrm{M}$, et al. Cryopyrin activates the inflammasome in response to toxins and ATP. Nature. 2006; 440: 228-32.

94. Zhou R, Tardivel A, Thorens B, Choi I, Tschopp J. Thioredoxininteracting protein links oxidative stress to inflammasome activation. Nat Immunol. 2010; 11: 136-40.

95. Heneka MT, Kummer MP, Stutz A, Delekate A, Schwartz S, VieiraSaecker A, et al. NLRP3 is activated in Alzheimer's disease and contributes to pathology in APP/PS1 mice. Nature. 2013; 493: 6748.

96. Halle A, Hornung V, Petzold GC, Stewart CR, Monks BG, Reinheckel $\mathrm{T}$, et al. The NALP3 inflammasome is involved in the innate immune response to amyloid-beta. Nat Immunol. 2008; 9: 857-65.

97. Busso N, So A. Mechanisms of inflammation in gout. Arthritis Res Ther. 2010; 12: 206. doi: 10.1186/ar2952.

98. Franklin BS, Bossaller L, De Nardo D, Ratter JM, Stutz A, Engels $\mathrm{G}$, et al. The adaptor ASC has extracellular and 'prionoid' activities that propagate inflammation. Nat Immunol. 2014; 15: 727-37.

99. Baroja-Mazo A, Martin-Sanchez F, Gomez AI, Martínez CM, AmoresIniesta J, Compan V, et al. The NLRP3 inflammasome is released as a particulate danger signal that amplifies the inflammatory response. Nat Immunol. 2014; 15: 738-48.

100. Odegaard JI, Chawla A. Alternative macrophage activation and metabolism. Annu Rev Pathol. 2011; 6: 275-97.

101. Ahmadian M, Wang Y, Sul HS. Lipolysis in adipocytes. Int J Biochem 
Cell Biol. 2010; 42: 555-9.

102. Björntorp P. Sjöström L, +SJOSTROM L: Number and size of adipose tissue fat cells in relation to metabolism in human obesity. Metabolism. 1971; 20: 703-13.

103. Landgraf K, Rockstroh D, Wagner IV, Weise S, Tauscher R, Schwartze JT, et al. Evidence of early alterations in adipose tissue biology and function and its association with obesity-related inflammation and insulin resistance in children. Diabetes. 2015; 64: 1249-61.

104. Hotamisligil GS, Shargill NS, Spiegelman BM. Adipose expression of tumor necrosis factor-alpha: direct role in obesity-linked insulin resistance. Science. 1993; 259: 87-91.

105. Ruderman NB, Schneider SH, Berchtold P. The "metabolicallyobese," normal-weight individual. Am J Clin Nutr. 1981; 34: 161721.

106. Lee YH, Mottillo EP, Granneman JG. Adipose tissue plasticity from WAT to BAT and in between. Biochim Biophys Acta. 2014; 1842: 358-69.

107. Lolmede K, Durand de Saint Front V, Galitzky J, Lafontan M, Bouloumie A. Effects of hypoxia on the expression of proangiogenic factors in differentiated 3T3-F442A adipocytes. Int J Obes Relat Metab Disord. 2003; 27: 1187-95.

108. Kaelin WG Jr, Ratcliffe PJ. Oxygen sensing by metazoans: the central role of the HIF hydroxylase pathway. Mol Cell. 2008; 30: 393-402.

109. Kosteli A, Sugaru E, Haemmerle G, Martin JF, Lei J, Zechner R, et al. Weight loss and lipolysis promote a dynamic immune response in murine adipose tissue. J Clin Invest. 2010; 120: 3466-79.

110. Lumeng CN, Deyoung SM, Bodzin JL, Saltiel AR. Increased inflammatory properties of adipose tissue macrophages recruited during diet-induced obesity. Diabetes. 2007; 56: 16-23.

111. Shoelson SE. Banking on ATM as a new target in metabolic syndrome. Cell Metab. 2006; 4: 337-8.

112. Bronte V, Serafini P, Mazzoni A, Segal DM, Zanovello P. L-arginine metabolism in myeloid cells controls T-lymphocyte functions. Trends Immunol. 2003; 24: 302-6.

113. Satriano J. Arginine pathways and the inflammatory response: interregulation of nitric oxide and polyamines: review article. Amino Acids. 2004; 26: 321-9.

114. Sun K, Scherer PE. Adipose Tissue Dysfunction: A Multistep Process. Berlin: Springer-Verlag Berlin Heidelberg; 2010.

115. Napolitano L. The differentiation of white adipose cells. An electron microscope study. J Cell Biol. 1963; 18: 663-79.

116. Chun TH, Hotary KB, Sabeh F, Saltiel AR, Allen ED, Weiss SJ. A pericellular collagenase directs the 3-dimensional development of white adipose tissue. Cell. 2006; 125: 577-91.

117. Khan T, Muise ES, Iyengar P, Wang ZV, Chandalia M, Abate N, et al. Metabolic dysregulation and adipose tissue fibrosis: role of collagen VI. Mol Cell Biol. 2009; 29: 1575-91.

118. O’Hara A, Lim FL, Mazzatti DJ, Trayhurn P. Microarray analysis identifies matrix metalloproteinases (MMPs) as key genes whose expression is up-regulated in human adipocytes by macrophageconditioned medium. Pflugers Arch. 2009; 458: 1103-14.

119. Berria R, Wang L, Richardson DK, Finlayson J, Belfort R, Pratipanawatr T, et al. Increased collagen content in insulin-resistant skeletal muscle. Am J Physiol Endocrinol Metab. 2006; 290: E5605.

120. Muona P, Jaakkola S, Zhang RZ, Pan TC, Pelliniemi L, Risteli L, et al. Hyperglycemic glucose concentrations up-regulate the expression of type VI collagen in vitro. Relevance to alterations of peripheral nerves in diabetes mellitus. Am J Pathol. 1993; 142: 1586-97.

121. Frayn KN. Adipose tissue as a buffer for daily lipid flux. Diabetologia. 2002; 45: 1201-10.

122. Guri AJ, Bassaganya-Riera J. Systemic effects of white adipose tissue dysregulation and obesity-related inflammation. Obesity. 2011; 19:
689-700.

123. Poirier P, Giles TD, Bray GA, Hong Y, Stern JS, Pi-Sunyer FX, et al. Obesity and cardiovascular disease: pathophysiology, evaluation, and effect of weight loss: an update of the 1997 American Heart Association Scientific Statement on Obesity and Heart Disease from the Obesity Committee of the Council on Nutrition, Physical Activity, and Metabolism. Circulation. 2006; 113: 898-918.

124. Bays HE, Gonzalez-Campoy JM, Bray GA, Kitabchi AE, Bergman $\mathrm{DA}$, Schorr AB, et al. Pathogenic potential of adipose tissue and metabolic consequences of adipocyte hypertrophy and increased visceral adiposity. Expert Rev Cardiovasc Ther. 2008; 6: 343-68.

125. Bays H, Abate N, Chandalia M. Adiposopathy: sick fat causes high blood sugar, high blood pressure and dyslipidemia. Future Cardiol. 2005; 1: 39-59.

126. Bays H, Ballantyne C. Adiposopathy: why do adiposity and obesity cause metabolic disease? Future Lipidol. 2006; 1: 389-420.

127. Bays HE. "Sick fat," metabolic disease, and atherosclerosis. Am J Med. 2009; 122 (Suppl 1): S26-37.

128. Bays HE, Gonzalez-Campoy JM, Henry RR, Bergman DA, Kitabchi $\mathrm{AE}$, Schorr $\mathrm{AB}$, et al. Is adiposopathy (sick fat) an endocrine disease? Int J Clin Pract. 2008; 62: 1474-83.

129. Bays HE. Adiposopathy is "sick fat" a cardiovascular disease? J Am Coll Cardiol. 2011; 57: 2461-73.

130. Trayhurn P, Wang B, Wood IS. Hypoxia and the endocrine and signalling role of white adipose tissue. Arch Physiol Biochem. 2008; 114: 267-76.

131. Bluher M. Adipose tissue dysfunction in obesity. Exp Clin Endocrinol Diabetes. 2009; 117: 241-50.

132. Kim KH, Song MJ, Chung J, Park H, Kim JB. Hypoxia inhibits adipocyte differentiation in a HDAC-independent manner. Biochem Biophys Res Commun. 2005; 333: 1178-84.

133. Rutkowski JM, Davis KE, Scherer PE. Mechanisms of obesity and related pathologies: the macro- and microcirculation of adipose tissue. FEBS J. 2009; 276: 5738-46.

134. Sun K, Tordjiman J, Clement K, Scherer PE. Fibrsis and adipose tissue dysfunction. Cell Metab. 2013; 18: 470-7.

135. Ye J. Emerging role of adipose tissue hypoxia in obesity and insulin resistance. Int J Obes. 2009; 33: 54-66.

136. de Ferranti S, Mozaffarian D. The perfect storm: obesity, adipocyte dysfunction, and metabolic consequences. Clin Chem. 2008; 54 : 945-55.

137. Zhou QG, Zhou M, Lou AJ, Xie D, Hou FF. Advanced oxidation protein products induce inflammatory response and insulin resistance in cultured adipocytes via induction of endoplasmic reticulum stress. Cell Physiol Biochem. 2010; 26: 775-86.

138. Nagai R, Brock JW, Blatnik M, Baatz JE, Bethard J, Walla MD, et al. Succination of protein thiols during adipocyte maturation: a biomarker of mitochondrial stress. J Biol Chem. 2007; 282: 3421928.

139. Van Gaal LF, Mertens IL, De Block CE. Mechanisms linking obesity with cardiovascular disease. Nature. 2006; 444: 875-80.

140. Blüher M. Clinical relevance of adipokines. Diabetes Metab J. 2012; 36: 317-27.

141. Bays HE. Adiposopathy, diabetes mellitus, and primary prevention of atherosclerotic coronary artery disease: treating "sick fat" through improving fat function with antidiabetes therapies. Am J Cardiol. 2012; 110 (Suppl 9): 4B-12B.

142. Tan CY, Vidal-Puig A. Adipose tissue expandability: the metabolic problems of obesity may arise from the inability to become more obese. Biochem Soc Trans. 2008; 36: 935-40.

143. Gealekman O, Guseva N, Hartigan C, Apotheker S, Gorgoglione $\mathrm{M}$, Gurav K, et al. Depot-specific differences and insufficient subcutaneous adipose tissue angiogenesis in human obesity. 
Circulation. 2011; 123: 186-94.

144. Lee MJ, Wu Y, Fried SK. Adipose tissue heterogeneity: implication of depot differences in adipose tissue for obesity complications. Mol Aspects Med. 2013; 34: 1-11.

145. Bays HE, Fox KM, Grandy S. Anthropometric measurements and diabetes mellitus: clues to the 'pathogenic' and 'protective' potential of adipose tissue. Metab Syndr Relat Disord. 2010; 8: 307-15.

146. Fox CS, Massaro JM, Hoffmann U, Pou KM, Maurovich-Horvat $\mathrm{P}$, Liu CY, et al. Abdominal visceral and subcutaneous adipose tissue compartments: association with metabolic risk factors in the Framingham Heart Study. Circulation. 2007; 116: 39-48.

147. Bays H. Central obesity as a clinical marker of adiposopathy; increased visceral adiposity as a surrogate marker for global fat dysfunction. Curr Opin Endocrinol Diabetes Obes. 2014; 21: 34551.

148. Tchoukalova YD, Koutsari C, Karpyak MV, Votruba SB, Wendland E, Jensen MD. Subcutaneous adipocyte size and body fat distribution. Am J Clin Nutr. 2008; 87: 56-63.

149. Stefan N, Kantartzis K, Machann J, Schick F, Thamer C, Rittig K, et al. Identification and characterization of metabolically benign obesity in humans. Arch Intern Med. 2008; 168: 1609-16.

150. Bluher M. Adipose tissue dysfunction contributes to obesity related metabolic diseases. Best Pract Res Clin Endocrinol Metab. 2013; 27: 163-77.

151. Yu BL, Zhao SP, Hu JR. Cholesterol imbalance in adipocytes: a possible mechanism of adipocytes dysfunction in obesity. Obes Rev. 2010; 11: 560-7.

152. Kovanen PT, Nikkilä EA, Miettinen TA. Regulation of cholesterol synthesis and storage in fat cells. J Lipid Res. 1975; 16: 211-23.

153. Schreibman PH, Dell RB. Human adipocyte cholesterol. Concentration, localization, synthesis, and turnover. J Clin Invest. 1975; 55: 986-93.

154. Guerre-Millo M, Guesnet P, Guichard C, Durand G, Lavau M. Alteration in membrane lipid order and composition in metabolically hyperactive fatty rat adipocytes. Lipids. 1994; 29: 205-9.

155. Le Lay S, Krief S, Farnier C, Lefrère I, Le Liepvre X, Bazin R, et al. Cholesterol, a cell size-dependent signal that regulates glucose metabolism and gene expression in adipocytes. J Biol Chem. 2001; 276: 16904-10.

156. Boizard M, Le Liepvre X, Lemarchand P, Foufelle F, Ferré P, Dugail I. Obesity-related overexpression of fatty-acid synthase gene in adipose tissue involves sterol regulatory element-binding protein transcription factors. J Biol Chem. 1998; 273: 29164-71.

157. Bluher M. The distinction of metabolically 'healthy' from 'unhealthy' obese individuals. Curr Opin Lipidol. 2010; 21: 38-43.

158. Wildman RP, Muntner P, Reynolds K, McGinn AP, Rajpathak S, Wylie- Rosett J, et al. The obese without cardiometabolic risk factor clustering and the normal weight with cardiometabolic risk factor clustering: prevalence and correlates of 2 phenotypes among the US population (NHANES 1999-2004). Arch Intern Med. 2008; 168: 1617-24.

159. De Gusmao Correia ML. Is 'metabolically healthy' obesity a benign condition? J Hypertens. 2013; 31: 39-41.

160. Ruderman N, Chisholm D, Pi-Sunyer X, Schneider S. The metabolically obese, normal-weight individual revisited. Diabetes. 1998; 47: 699-713.

161. Goodarzi MO, Dumesic DA, Chazenbalk G, Azziz R. Polycystic ovary syndrome: etiology, pathogenesis and diagnosis. Nat Rev Endocrinol. 2011; 7: 219-31.

162. Lee K. Metabolically obese but normal weight (MONW) and metabolically healthy but obese (MHO) phenotypes in Koreans: characteristics and health behaviors. Asia Pac J Clin Nutr. 2009; 18: 280-4.
163. Ruderman NB, Berchtold P, Schneider S. Obesity-associated disorders in normal weight individuals: some speculations. Int $\mathrm{J}$ Obes. 1982; 6 (Suppl 1): 151-7.

164. Denis GV, Obin MS. 'Metabolically healthy obesity': origins and implications. Mol Aspects Med. 2013; 34: 59-70.

165. Pescovitz MD, Greenbaum CJ, Krause-Steinrauf H, Becker DJ, Gitelman SE, Goland R, et al. Rituximab, B-lymphocyte depletion, and preservation of beta-cell function. N Engl J Med. 2009; 361: 2143-52.

166. Payne GA, Kohr MC, Tune JD. Epicardial perivascular adipose tissue as a therapeutic target in obesity-related coronary artery disease. $\mathrm{Br}$ J Pharmacol. 2012; 165: 659-69.

167. Konishi M, Sugiyama S, Sugamura K, Nozaki T, Ohba K, Matsubara $\mathrm{J}$, et al. Association of pericardial fat accumulation rather than abdominal obesity with coronary atherosclerotic plaque formation in patients with suspected coronary artery disease. Atherosclerosis. 2010; 209: 573-8.

168. Taguchi R, Takasu J, Itani Y, Yamamoto R, Yokoyama K, Watanabe $\mathrm{S}$, et al. Pericardial fat accumulation in men as a risk factor for coronary artery disease. Atherosclerosis. 2001; 157: 203-9.

169. Bouchard C, Tremblay A, Després JP, Nadeau A, Lupien PJ, Thériault $\mathrm{G}$, et al. The response to long-term overfeeding in identical twins. N Engl J Med. 1990; 322: 1477-82.

170. Wajchenberg BL. Subcutaneous and visceral adipose tissue: their relation to the metabolic syndrome. Endocr Rev. 2000; 21: 697-738.

171. Després JP, Moorjani S, Lupien PJ, Tremblay A, Nadeau A, Bouchard C. Genetic aspects of susceptibility to obesity and related dyslipidemias. Mol Cell Biochem. 1992; 113: 151-69.

172. Strissel KJ, Denis GV, Nikolajcyk BS. Immune regulators of inflammation in obesity-associated type 2 diabetes and coronary artery disease. Curr Opin Endocrinol Diabetes Obes. 2014; 21: 3308.

173. Spencer M, Yao-Borengasser A, Unal R, Rasouli N, Gurley CM, Zhu $\mathrm{B}$, et al. Adipose tissue macrophages in insulin-resistant subjects are associated with collagen VI and fibrosis and demonstrate alternative activation. Am J Physiol Endocrinol Metab. 2010; 299: E1016-27.

174. Pasarica M, Gowronska-Kozak B, Burk D, Remedios I, Hymel $\mathrm{D}$, Gimble J, et al. Adipose tissue collagen VI in obesity. J Clin Endocrinol Metab. 2009; 94: 5155-62.

175. Huang Y, Yan X, Zhu MJ, McCormick RJ, Ford SP, Nathanielsz $\mathrm{PW}$, et al. Enhanced transforming growth factor-beta signaling and fibrogenesis in ovine fetal skeletal muscle of obese dams at late gestation. Am J Physiol Endocrinol Metab. 2010; 298: E1254-60.

176. Patti ME, Butte AJ, Crunkhorn S, Cusi K, Berria R, Kashyap S, et al. Coordinated reduction of genes of oxidative metabolism in humans with insulin resistance and diabetes: potential role of PGC1 and NRF1. Proc Natl Acad Sci USA. 2003; 100: 8466-71.

177. Combs TP, Pajvani UB, Berg AH, Lin Y, Jelicks LA, Laplante M, et al. A transgenic mouse with a deletion in the collagenous domain of adiponectin displays elevated circulating adiponectin and improved insulin sensitivity. Endocrinology. 2004; 145: 367-83.

178. Pischon T, Girman CJ, Hotamisligil GS, Rifai N, Hu FB, Rimm EB. Plasma adiponectin levels and risk of myocardial infarction in men. JAMA. 2004; 291: 1730-7.

179. Ohashi K, Parker JL, Ouchi N, Higuchi A, Vita JA, Gokce N, et al. Adiponectin promotes macrophage polarization towards an antiinflammatory phenotype. J Biol Chem. 2010; 285: 6153-60.

180. Nikolajczyk BS, Jagannathan-Bogdan M, Denis GV. The outliers become a stampede as immunometabolism reaches a tipping point. Immunol Rev. 2012; 249: 253-75.

181. Succurro E, Marini MA, Frontoni S, Hribal ML, Andreozzi F, Lauro $\mathrm{R}$, et al. Insulin secretion in metabolically obese, but normal weight, and in metabolically healthy but obese individuals. Obesity. 2008 ; 
16: $1881-6$.

182. Berg AH, Scherer PE. Adipose tissue, inflammation, and cardiovascular disease. Circ Res. 2005; 96: 939-49.

183. Matsuzawa Y. Therapy insight: adipocytokines in metabolic syndrome and related cardiovascular disease. Nat Clin Pract Cardiovasc Med. 2006; 3: 35-42.

184. Aguilar-Salinas CA, García EG, Robles L, Riaño D, Ruiz-Gomez DG, García-Ulloa AC, et al. High adiponectin concentrations are associated with the metabolically healthy obese phenotype. J Clin Endocrinol Metab. 2008; 93: 4075-9.

185. Toulis KA, Goulis DG, Farmakiotis D, Georgopoulos NA, Katsikis I, Tarlatzis BC, et al. Adiponectin levels in women with polycystic ovary syndrome: a systematic review and a meta-analysis. Hum Reprod Update. 2009; 15: 297-307.

186. Achilike I, Hazuda HP, Fowler SP, Aung K, Lorenzo C. Predicting the development of the metabolically healthy obese phenotype. Int J Obes. 2015; 39: 228-34.

187. Mechanick JI, Garber AJ, Handelsman Y, Garvey WT. American Association of Clinical Endocrinologists' position statement on obesity and obesity medicine. Endocr Pract. 2012; 18: 642-8.

188. NHLBI Obesity Education Initiative Expert Panel on the Identification, Evaluation, and Treatment of Overweight and Obesity in Adults. Clinical Guidelines on the Identification, Evaluation, and Treatment of Overweight and Obesity in Adults: the evidence report. National Institute of Health. Obes Res. 1998; 6 (Suppl 2): 51S-209S.

189. Kolotkin RL, Meter K, Williams GR. Quality of life and obesity. Obes Rev. 2001; 2: 219-29.

190. World Health Organization. Obesity: preventing and managing the global epidemic. Geneva: World Health Organization; 1998.

191. Malnick SDH, Knobler H. The medical complications of obesity. Q J Med. 2006; 99: 565-79.

192. Behnke A, Wilmore J. Evaluation and regulation of body build and composition. New Jersey: Prentice Hall; 1974.

193. Wellens RI, Roche AF, Khamis HJ, Jackson AS, Pollock ML, Siervogel RM. Relationships between the body mass index and body composition. Obes Res. 1996; 4: 35-44.

194. Kontogianni MD, Panagiotakos DB, Skopouli FN. Does body mass index reflect adequately the body fat content in perimenopausal women? Maturitas. 2005; 51:307-13.

195. Prentice AM, Jebb SA. Beyond body mass index. Obes Rev. 2001; 2 : 141-7.

196. World Health Organization. The Asia-Pacific Perspective: redefining obesity and its treatment. Sydney; Health Communications Australia Pty Limited: 2000.

197. Banerji MA, Faridi N, Atluri R, Chaiken RL, Lebovitz HE. Body composition, visceral fat, leptin, and insulin resistance in Asian Indian men. J Clin Endocrinol Metab. 1999; 84: 137-44.

198. Daniel S, Soleymani T, Garvey WT. A complications-based clinical staging of obesity to guide treatment modality and intensity. Curr Opin Endocrinol Diabetes Obes. 2013; 20: 377-88.

199. Welborn TA, Dhaliwal SS, Bennett SA. Waist-hip ratio is the dominant risk factor predicting cardiovascular death in Australia. Med J Aust. 2003; 179: 580-5.

200. Lawlor DA, Davey Smith G, Ebrahim S. Life course influences on insulin resistance: findings from the British Women's Heart and
Health Study. Diabetes Care. 2003; 26: 97-103.

201. Janssen I, Katzmarzyk PT, Ross R. Body mass index, waist circumference, and health risk: evidence in support of current National Institutes of Health guidelines. Arch Intern Med. 2002; 162: 2074-9.

202. Liao Y, Kwon S, Shaughnessy S, Wallace P, Hutto A, Jenkins AJ, et al. Critical evaluation of adult treatment panel III criteria in identifying insulin resistance with dyslipidemia. Diabetes Care. 2004; 27: 97883.

203. Lara-Castro C, Garvey WT. Diet, insulin resistance, and obesity: zoning in on data for Atkins dieters living in South Beach. J Clin Endocrinol Metab. 2004; 89: 4197-205.

204. Wormser D, Kaptoge S, Di Angelantonio E, Wood AM, Pennells L, Thompson A, et al. Separate and combined associations of bodymass index and abdominal adiposity with cardiovascular disease: collaborative analysis of 58 prospective studies. Lancet. 2011; 377: 1085-95.

205. Wildman RP, Muntner P, Reynolds K, McGinn AP, Rajpathak S, Wylie-Rosett J, et al. The obese without cardiometabolic risk factor clustering and the normal weight with cardiometabolic risk factor clustering: prevalence and correlates of 2 phenotypes among the US population (NHANES 1999-2004). Arch Intern Med. 2008; 168: 1617-24.

206. Ferrannini E, Balkau B, Coppack SW, Dekker JM, Mari A, Nolan J, et al. Insulin resistance, insulin response, and obesity as indicators of metabolic risk. J Clin Endocrinol Metab. 2007; 92: 2885-92.

207. Apovian CM, Mechanick JI. Obesity IS a disease! Curr Opin Endocrinol Diabetes Obes. 2013; 20: 367-8.

208. Phillips CM, Perry IJ. Does inflammation determine metabolic health status in obese and nonobese adults? J Clin Endocrinol Metab. 2013; 98: E1610-9.

209. Garvey WT. New tools for weight loss therapy enable a more robust medical model for obesity treatment: rationale for a complicationscentric model. Endocr Pract. 2013; 19: 864-74.

210. Padwal RS, Pajewski NM, Allison DB, Sharma AM. Using the Edmonton obesity staging system to predict mortality in a population-representative cohort of people with overweight and obesity. CMAJ. 2011; 183: E1059-66.

211. Guo F, Garvey WT. A new cardiometabolic risk staging system to guide treatment for obesity using a complications-centric approach: validation using CARDIA and NHANES data. American Association of Clinical Endocrinologists 22nd Annual Scientific and Clinical Congress; 2013. p. Abstract \#603.

212. Garber AJ, Abrahamson MJ, Barzilay JI, Blonde L, Bloomgarden ZT, Bush MA, et al. AACE comprehensive diabetes management algorithm. Endocr Pract. 2013; 19: 327-36.

213. Klein S, Burke LE, Bray GA, Blair S, Allison DB, Pi-Sunyer X, et al. Clinical implications of obesity with specific focus on cardiovascular disease: a statement for professionals from the American Heart Association Council on Nutrition, Physical Activity, and Metabolism: endorsed by the American College of Cardiology Foundation. Circulation. 2004; 110: 2952-67.

214. Sharma AM, Kushner R. A proposed clinical staging system for obesity. Int J Obes. 2009; 33: 289-95. 